\title{
Transient Investigation of Stack-driven Air Flow Through Multiple Upper-vents in the Presence of Constant Indirect Flow Velocity in Rectangular Ventilated Building
}

\author{
Muhammad Auwal Lawan, Sunusi Aminu Nata'ala \\ Department of Mathematics, Kano University of Science and Technology, Wudil, Nigeria \\ Email address: \\ mukhazah3@gmail.com (M. A. Lawan), sunusiaminunataala@gmail.com (S. A. Nata'ala) \\ ${ }^{*}$ Corresponding author
}

To cite this article:

Muhammad Auwal Lawan, Sunusi Aminu Nata'ala. Transient Investigation of Stack-driven Air Flow Through Multiple Upper-vents in the Presence of Constant Indirect Flow Velocity in Rectangular Ventilated Building. Engineering Mathematics. Vol. 4, No. 2, 2020 , pp. 14-30. doi: 10.11648/j.engmath.20200402.11

Received: September 25, 2019; Accepted: October 21, 2019; Published: September 3, 2020

\begin{abstract}
The paper investigates the time independent effect of Stack- driven airflow in cross- ventilated building with multiple opening in the presence of constant indirect flow velocity. The dimensionless model of momentum and energy equations are analyzed, using second order linear differential equation to develop the explicit expression for velocity, temperature profiles together with volumetric and mass- transfer by means of separation of variable method. Some numerical examples are presented graphically in order to illustrate the effects of physical parameters involved in the study. From the course of investigation, it was observed air temperature and velocity increase with the increase in both parameters $\left(\theta_{0}\right),(P r)$ and $(G r)$. Respectively. In addition, comparison with previously published work by A. L. Muhammad et. al (2016) was performed. In which, the study concluded that, the results for present work is more effective and efficient than the previous work in term of ventilation process. Finally, from the course of investigation, it was observed air temperature and velocity increase with the increase in both parameters $\left(\theta_{0}\right),(P r)$ and $(G r)$ respectively.
\end{abstract}

Keywords: Transient Effect, Indirect Flow Velocity, Multiple Upper Vents, Ventilated Building

\section{Introduction}

From a technological point of view, a study of natural ventilation in building is always important. The analysis of such flows finds application in different areas such as Fluid dynamics, architectural design and Engineering. Natural ventilation of building provides improvement of internal comfort and air quality conditions leading to a significant reduction of cooling energy consumption. Design of natural ventilation systems for many types of building is based on buoyancy forces. However, external wind flow can have significant effects on buoyancy- driven natural ventilation. Air flow distributions in buildings are considered to be as a result of the knowledge of the exact air supply to a building. Knowledge of the exact air supply to a building is necessary to determine its thermal performance and the concentration of the indoor pollutants. The exchange of air can be achieved either by mechanical means (Mechanical ventilation) or through the large opening of the building envelope (Natural ventilation). Of course natural ventilation is being pursued by humans, who are increasingly spending more time indoors, to extend the possibilities of living in uncongenial or squally conditions etc. The improvements of the quality of the interior space both in its attractiveness, spaciousness, luminosity, and more importantly its proper natural ventilation are major concerns for designers of modern structures. Air flow modeling gives Architectures and Engineers the luxury to consider several design options in the minimum amount of time. As a result, the final design is not based on a tentative approach, but is a result of a professional design process considering several options and selecting the optimum solution. This can save on capital and running costs save time on commissioning. Many attempts to investigate this phenomenon have been made by some researchers such as, investigated airflow process in single-sided natural ventilation was given [1]. The CFD model was applied to 
determine the effects of buoyancy, wind or their combination on ventilation rates and indoor conditions. A scale effect in room air-flow was presented [2] and later air movement on naturally-ventilated building was studied [3]. And also an investigation of air flow rate across a vertical opening which is induced by thermal source in a room was given [4] and worked based on the study [3]. Stack- driven airflow through rectangular cross- ventilated building with two openings using analytic technique was presented [5] and steady airflow through multiple upper openings inside a rectangular building in the presence of indirect flow was also investigated [6]. An example of solution multiplicity in a building with bi-directional flow openings was presented [7]. CFD model of airflow air indoor pollutant in rooms was presented [8]. A room airflow distribution system using CFD was presented [9]. An approach with advantages and disadvantages of various methods for modeling air flow in the building was described [10] and also studies buoyancydriven natural ventilation of buildings-impact of computational domain. Displacement ventilation (where the interior is stratified) was presented by ([11] and the mixing ventilation (where the interior has uniform temperature) was presented [12]. Airflow process that combined the ideas of displacement ventilation from [14] was studied [13]. A transient airflow process across three vertical vents induced by Stack- driven effect inside Un- Stratified cross- ventilated rectangular building with an opposing flow in one of the upper Opening was studied [15]. Mathematical modeling of wind forces was developed [16].

A flexible system- identification frame-work for linear thermal models that is well suited to accommodate the unique features of mixed-mode buildings was presented [17]. ventilation driven by a point source of buoyancy on the floor of an enclosure in the presence of wind was examined [18]. natural ventilation potential by considering thermal comfort issues was presented [20] and estimated [19]. heat and masstransfer through an openings by natural convection in a single sided ventilated building was studied [21] and the study also obtained an equation that predicts velocity distributions, volumetric airflow and mass transfer in terms of stack-effect using Bernoulli's equation for an in viscid fluid. 3D unsteady Reynolds-averaged Navier-Stokes (RANS) CFD simulations to reproduce the decay of $\mathrm{CO}_{2}$ (Carbon dioxide) concentration in a large semi-enclosed stadium was presented by [22]. A study of two openings naturally ventilated building potential model considering solution multiplicity, window opening percentage, air velocity and humidity in China was presented [23]. An experiment on the exchange flow through a window in a heated, sealed room of a test house was performed [24]. The data give a smaller value of discharge coefficient $C_{d}=0.044+0.004 \Delta T$ and suggested that the reduction was coused by mixing of the incoming and outgoing air at the window.

An experiment on a vertical temperature distribution of hybrid ventilation in an atrium building was performed [25]. full- scale experimental and CFD methods were used to investigated buoyancy- driven single sided natural ventilation with large openings [26]. An experimental analysis on a single full size ventilated box window without shading devices was performed [27]. A building having two openings at different vertical level on opposite walls with heights of the two openings are relatively small was studied [28]. The study also considered an indoor source of heat $E$, and the wind force can assist or oppose the thermal buoyancy force, when the indoor temperature is uniform. Natural ventilation induced by combined wind and thermal forces was studied [29]. Interaction of the wind with building by considering the wind-driven flow only was investigated [30]. Wind driven cross ventilation in buildings with small openings was studied [31]. A simple mathematical model of stack ventilation flows in multi-compartment buildings was presented [32]. A non- dimensional analytical method was used [33] to calculate the overall heat transfer coefficient and energy balance of a DSF. A study of natural ventilation in an enclosure containing two buoyancy forces was presented [34]. A macroscopic model that describes natural convection through rectangular openings in partition-I in a single sided ventilated building was investigated [35]. A macroscopic model that describes natural convection through rectangular openings in partition-II in a single sided ventilated building was also presented [36]. A study of fluid mechanics of natural ventilation was given [37]. CFD and Field Testing of a naturally ventilated Full-scale Building was experimentally study [38]. A transient investigation of airflow through two upper openings in a cross ventilated rectangular building in the absence of opposing flow was study [39].

The main objective of this paper is to analytically determine the behavior of parameters involve in the results which can predicts the temperature, velocity profiles together with volumetric airflow and mass transfer in a rectangular un- stratified cross- ventilated building with multiple openings on a vertical wall. Results of the computations for velocity, temperature distributions together with volumetric flow and mass transfer will be present graphically and various parameters such as Effective thermal coefficient $\left(\theta_{0}\right)$, Prandtl number $(P r)$ and Grashof number $(G r)$ embedded in the problem will be discuss. In addition, comparison with previously published work will be perform in order to ascertain the best for optimal ventilation. This is the novel approach which will lead to better understanding of the phenomenon and help in optimizing the designs for better natural ventilation.

\section{Description/ Statement of Problem}

In this paper, a theoretical study for transient effect of constant indirect flow velocity through multiple upper- vents in rectangular building was considered. A flow of this type represents a new class of boundary- layer flow problems in the building envelope. Moreover, this is an exact solution of the complete Navier- Stokes Equations (including, buoyancy force term). The building considered, is un-stratified crossventilated rectangular building with multiple openings. In which the building has Five (5) upper and one lower rectangular opening. The upper opening has an area of $0.7 \mathrm{~m} \times 1.0 \mathrm{~m}$, while the lower opening is $0.7 \mathrm{~m} \times 2.0 \mathrm{~m}$. Dimension of the building is $5.3 \mathrm{~m} \times 3.6 \mathrm{~m} \times 2.8 \mathrm{~m}$ with air 
as the connecting fluid. The domain envelops were separated from one another by a vertical rectangular openings of height $y^{*}$ and width $x_{w}$, which is illustrated in Figure 1. The density of air in the building is maintained at $\rho_{0}$ with temperature at $T$ and pressure $P$.

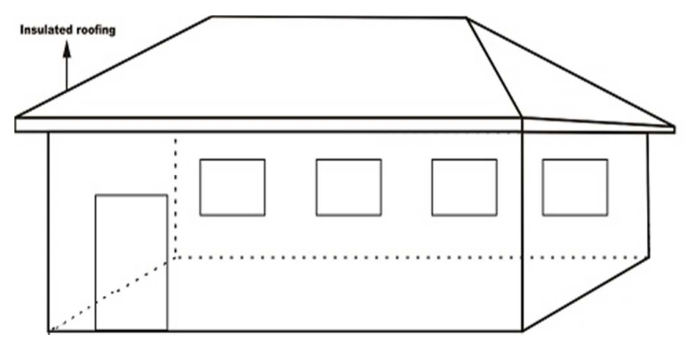

Figure 1. Diagram of un-stratified ventilated rectangular building with multiple- vents.

\section{Material and Method}

In the present paper we discussed the temperature- velocityprofiles together with volumetric and mass transfer for transient Stack- driven airflow through rectangular openings in building with multiple openings in the presence of uniform interior temperature (see Figure 1). A schematic diagram of airflow process in the building is shown in Figures 2 and 3 below. The flow is transient that depends on the height of the opening on the vertical walls. Airflow is assumed to be at low speed so that it will behave like incompressible fluid. Internal heat source is negligible $q \ll 1$ (see Figure 1). An approximation of reduced gravity is invoked. One Navier Stokes Equations with appropriate boundary conditions will describe the problem. The model equations are written in a dimensionless form and solved analytically by means of separation of variable methods.

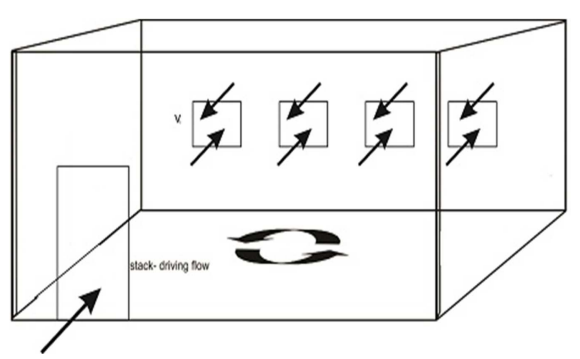

Figure 2. Schematic diagram of airflow process in the ventilated rectangular building with multiple- upper vents.

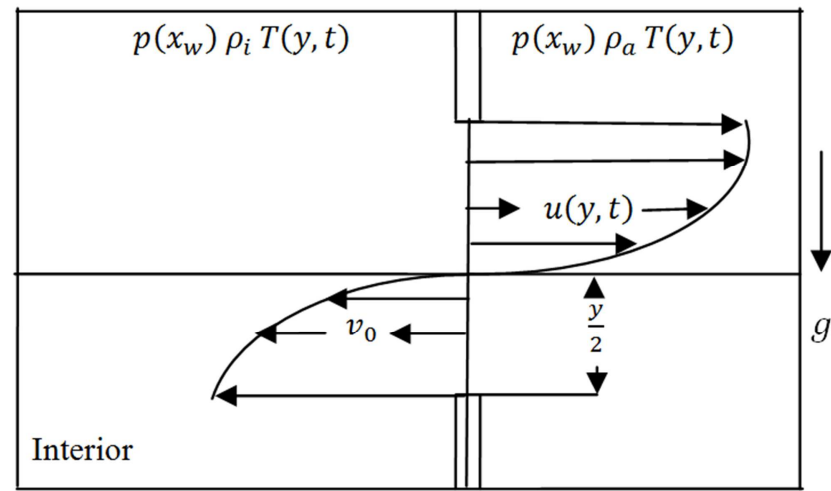

Figure 3. Schematic diagram of indirect flow in each of the multiple-vertical vents in rectangular building.
Notations and Greek's words

$C_{1}, C_{2}, C_{3}, C_{4}, C_{5}, C_{6}$ coefficients

$P_{1}, P_{2}$

$K, d, C$

separation constants

$A_{T}$

$q$

L

$v_{0}$

$p$

$g$

$x_{w}$

$c_{p}$

$S$

$Y^{*}$

Y

$t$

$t^{*}$

$c_{d}$

$U_{0}$

$U$

$U^{*}$

$U_{S}^{*}$

$U_{u}^{*}$

$U_{c}^{*}$

$U_{p}^{*}$

Greek symbols

$\rho_{a} \quad$ ambient density of air

$\rho_{i} \quad$ interior density of air

$T_{a} \quad$ ambient temperature of air

$\theta_{0} \quad$ effective thermal coefficient

$\theta \quad$ air temperature in dimensional form

$\Delta \theta \quad$ change of air temperature in dimensional form

$T^{*} \quad$ temperature profile in non- dimensional form

$T_{s}^{*} \quad$ steady temp. profile in non- dimensional form

$T_{u}^{*} \quad$ unsteady temp. profile in non- dimensional form

$\beta \quad$ coefficient of thermal expansion

$\alpha \quad$ thermal conductivity ratio

$v \quad$ kinematic viscosity of fluid

$\mu \quad$ dynamic viscosity of fluid

$\kappa \quad$ coefficient of thermal diffusivity

$\phi_{v} \quad$ viscous dissipation

Non dimensional Group
$\mathrm{Pr}$
$\mathrm{Gr}$

S
Prandtl number

Grashof number

width of the openings 


\section{Model Formulation}

The convective motion induced by stack- driven effect as illustrated in Figures 2 and 3 is described by the conservation Equations for Continuity, Momentum and Energy Equations known as Navier- Stokes Equations,

$$
\begin{gathered}
\rho_{a}\left(\frac{\partial U}{\partial x_{w}}+\frac{\partial v_{0}}{\partial Y^{*}}\right)=0 \\
\rho_{0}\left(\frac{\partial U}{\partial t}+U \frac{\partial U}{\partial x_{w}}+v_{0} \frac{\partial v_{0}}{\partial Y^{*}}\right)=-\frac{d p}{d x_{w}}+\mu\left(\frac{\partial^{2} U}{\partial x_{w}^{2}}+\frac{\partial^{2} U}{\partial Y^{* 2}}\right) \\
\rho_{0}\left(\frac{\partial \theta}{\partial t}+U \frac{\partial \theta}{\partial x_{w}}+v_{0} \frac{\partial \theta}{\partial Y^{*}}\right)=-\frac{\kappa}{c_{p}}\left(\frac{\partial^{2} \theta}{\partial x_{w}^{2}}+\frac{\partial^{2} \theta}{\partial Y^{*}}\right)+\frac{q}{c_{p}} \phi_{v}
\end{gathered}
$$

It assumed that the velocity and temperature fields are independent of the distance parallel to the surface, and if the gravitational field is aligned with the direction of air motion, the pressure will be a component along the width of the openings in the building, and air as no viscous fluid, we can neglect the viscous dissipation as $\phi_{v} \ll 1$ and $q \ll 1$,

$$
U=U\left(Y^{*}, t\right), v=v_{0}=\text { const. }, \theta=\theta(y, t)
$$

Navier- Stokes Equations are simplified by the above mentioned assumptions, in which continuity Equation in (1) is satisfied identically then, Equations (2) and (3) can be reduces to,

$$
\begin{gathered}
\frac{\partial U}{\partial t}+v_{0} \frac{\partial U}{\partial Y^{*}}=g \beta \Delta T+v \frac{\partial^{2} U}{\partial Y^{* 2}} \\
\frac{\partial \theta}{\partial t}+v_{0} \frac{\partial \theta}{\partial Y^{*}}=\alpha \frac{\partial^{2} \theta}{\partial Y^{* 2}}
\end{gathered}
$$

With the following dimensional boundary conditions as,

$$
\begin{gathered}
0 \leq Y^{*} \leq 2, t \geq 0, v=v_{0}=\text { const. }, U(0)=0, U(2) \\
=0, U(0, t)=0, U(2, t)=0 \\
\theta(0)=-\theta_{0}, \theta(2)=1-\theta_{0}, \theta(0, t)=0, \theta(2, t)=0
\end{gathered}
$$

By scaling $Y^{*}$ with $Y L$, velocity $u$ with $\frac{U^{*} g \beta \Delta \theta L^{2}}{\alpha}, t=\frac{t^{*} L^{2}}{\alpha}$, and introducing $\theta$ with $T^{*} \Delta \theta+T_{a}$.

In dimensionless form the above Equations (5) and (6) may be expressed as,

$$
\begin{gathered}
\frac{\partial U^{*}}{\partial t^{*}}-C \frac{\partial U^{*}}{\partial Y}=\frac{\partial^{2} U^{*}}{\partial Y^{2}}+\operatorname{PrGr} T^{*}\left(Y, t^{*}\right) \\
\frac{\partial T^{*}}{\partial t^{*}}-C \frac{\partial T^{*}}{\partial Y}=\frac{\partial^{2} T^{*}}{\partial Y^{2}}
\end{gathered}
$$

Where, $C=-v_{0} P r$,

with the following dimensionless boundary conditions as,

$$
\begin{gathered}
0 \leq Y \leq 1, t^{*} \geq 0, U(0)=0, U(1)=0, U_{u}\left(0, t^{*}\right)=0, U_{u}\left(1, t^{*}\right)=0, \frac{\partial U\left(1, t_{\max }\right)}{\partial Y}=U_{0}, \\
T^{*}(0)=-\theta_{0}, T^{*}(1)=1-\theta_{0}, T_{u}^{*}\left(0, t^{*}\right)=0, T_{u}^{*}\left(1, t^{*}\right)=0, T_{u}^{*}\left(1, t_{\max }\right)=\operatorname{sint}^{*}
\end{gathered}
$$

The time dependent Equation given in Equation (9) is,

$$
\frac{\partial T^{*}}{\partial t^{*}}-C \frac{\partial T^{*}}{\partial Y}=\frac{\partial^{2} \dot{T}^{*}}{\partial Y^{2}}
$$

Together with dimensionless boundary conditions as,

$$
0 \leq Y \leq 1, t^{*} \geq 0, T^{*}(0)=-\theta_{0}, T^{*}(1)=1-\theta_{0}, T_{u}^{*}\left(0, t^{*}\right)=0, T_{u}^{*}\left(1, t^{*}\right)=0, T_{u}^{*}\left(1, t_{\max }\right)=\operatorname{sint} t^{*}
$$

The steady state Equation and steady boundary condition for dimensionless temperature profiles is,

$$
\begin{gathered}
\frac{d^{2} T^{*}}{d Y^{2}}+C \frac{\partial T^{*}}{\partial Y}=0 \\
0 \leq Y \leq 1, T^{*}(0)=-\theta_{0}, T^{*}(1)=1-\theta_{0}
\end{gathered}
$$

Equation (12), together with the homogeneous dimensionless boundary conditions in Equations (13) yields to,

$$
T_{s}^{*}(Y)=-\theta_{0}+\frac{e^{C}}{1-e^{C}}\left(e^{-C Y}-1\right)
$$

The Equation for the temperature profiles is one given in Equation (9) as,

$$
\frac{\partial T^{*}}{\partial t^{*}}-C \frac{\partial T^{*}}{\partial Y}=\frac{\partial^{2} \dot{T}^{*}}{\partial Y^{2}}
$$

The separation between the steady and unsteady part of solution are as follows,

$$
T^{*}\left(Y, t^{*}\right)=T^{*}{ }_{s}(Y)+T_{u}^{*}\left(Y, t^{*}\right)
$$

The Equation (9) is also valid for the unsteady part of the solution as,

$$
\frac{\partial T_{u}^{*}}{\partial t^{*}}-C \frac{\partial T_{u}^{*}}{\partial Y}=\frac{\partial^{2} T_{u}^{*}}{\partial Y^{2}}
$$

With the following unsteady boundary condition for dimensionless temperature profiles as,

$0 \leq Y \leq 1, T_{u}^{*}\left(0, t^{*}\right)=0, T_{u}^{*}\left(1, t^{*}\right)=0, T_{u}^{*}\left(1, t_{\max }\right)=\sin t^{*}$

The separation given by,

$$
T_{u}^{*}\left(Y, t^{*}\right)=Y(Y) T\left(t^{*}\right)
$$

Leads with Equation (16) to the eigen value problem as,

$$
\frac{T^{\prime}}{T}=\frac{Y^{\prime \prime}}{Y}+\frac{C Y^{\prime}}{Y}=-P_{1}^{2} \text { for } P_{1}>0
$$

In which Equation (18) yields to, 
$T_{u}^{*}\left(Y, t^{*}\right)=e^{-P_{1}^{2} t}\left(K_{1} e^{\left(\frac{-C+\sqrt{C^{2}-4 P_{1}^{2}}}{2}\right) Y}+K_{2} e^{\left(\frac{-C-\sqrt{C^{2}-4 P_{1}^{2}}}{2}\right) Y}\right)$

With generalized solution of the form,

$$
T_{u}^{*}\left(Y, t^{*}\right)=e^{-\left(P_{1}^{2} t+\frac{C}{2}\right)}\left(C_{1} \cosh d Y+C_{2} \sinh d Y\right)
$$

For, $0<P_{1} \leq \frac{c}{2}, d=\sqrt{C^{2}-4 P_{1}^{2}}$ and the arbitrary constants $K_{1}=C_{1}+C_{2}, K_{2}=C_{1}-C_{2}$.

Equation (20), together with the homogeneous dimensionless boundary conditions in Equations (17) yields to,

$$
T_{u}^{*}\left(Y, t^{*}\right)=\frac{\sin t^{*}}{\cosh d} e^{\left(P_{1}^{2}\left(t_{\max }-t^{*}\right)+\frac{C}{2}\right)} \cosh Y Y
$$

Where, $C_{1}=0, C_{2}=\frac{\sin t^{*}}{\cosh d} e^{\left(P_{1}^{2} t_{\max }+\frac{C}{2}\right)}$ for, $d=\frac{\sqrt{C^{2}-4 P_{1}^{2}}}{2}$ at $t^{*} \geq 0$.

The time dependent solution for dimensionless temperature profiles is,

$$
T^{*}\left(Y, t^{*}\right)=-\theta_{0}+\frac{e^{C}}{1-e^{C}}\left(e^{-C Y}-1\right)+\frac{\sin t^{*}}{\operatorname{coshd}} e^{\left(P_{1}^{2} t_{\max }-t^{*}\right)} \cosh d Y
$$

The time dependent Equation given in Equation (8) is,

$$
\begin{gathered}
\frac{\partial U^{*}}{\partial t^{*}}-C \frac{\partial U^{*}}{\partial Y}=\frac{\partial^{2} U^{*}}{\partial Y^{2}}+\operatorname{Pr} \operatorname{Cr} T^{*}\left(Y, t^{*}\right) \\
\frac{\partial U^{*}}{\partial t^{*}}-C \frac{\partial U^{*}}{\partial Y}=\frac{\partial^{2} U^{*}}{\partial Y^{2}}+\operatorname{Pr} G r\left(-\theta_{0}+\frac{e^{C}}{1-e^{C}}\left(e^{-C Y}-1\right)+\frac{\sin t^{*}}{\cosh d} e^{\left(P_{1}^{2} t_{\max }-t^{*}\right)} \cosh d Y\right)
\end{gathered}
$$

Together with dimensionless boundary conditions as,

$$
0 \leq Y \leq 1, t^{*} \geq 0, U^{*}(0)=0, U^{*}(1)=0, U_{u}^{*}\left(0, t^{*}\right)=0, U_{u}^{*}\left(1, t^{*}\right)=0, \frac{\partial U^{*}\left(1, t_{\max }\right)}{\partial Y}=U_{0}
$$

\section{Steady Solution}

The steady state Equation and boundary condition for dimensionless velocity profiles is,

$$
\begin{gathered}
\frac{\partial^{2} U^{*}}{\partial Y^{2}}+C \frac{\partial U^{*}}{\partial Y}=\operatorname{PrGr}\left(-\theta_{0}+\frac{e^{C}}{1-e^{C}}\left(e^{-C Y}-1\right)\right) \\
0 \leq Y \leq 1, U^{*}(0)=0, U^{*}(1)=0
\end{gathered}
$$

Starting with the homogeneous part of Equation (16), one obtained the complementary solution as,

$$
U_{c}^{*}(Y)=C_{3}+C_{4} e^{v_{0} Y}
$$

By employing the variation of parameter methods, one can write the particular solution as,

$$
U_{p}^{*}(Y)=\frac{G r}{C^{2}\left(1-e^{-C}\right)}\left[\left(\theta_{0}\left(1-e^{-C}\right)-1\right) C Y-e^{-C Y}\left(1+\frac{1}{1-P r}\right)+\operatorname{Pr}\left(1-\theta_{0}\left(1-e^{-C}\right)\right)\right]
$$

The general solution is given by,

$$
U_{s}^{*}(Y)=C_{3}+C_{4} e^{v_{0} Y}+\frac{G r}{C^{2}\left(1-e^{-C}\right)}\left[\left(\theta_{0}\left(1-e^{-C}\right)-1\right) C Y-e^{-C Y}\left(1+\frac{1}{1-P r}\right)+\operatorname{Pr}\left(1-\theta_{0}\left(1-e^{-C}\right)\right)\right]
$$

The two constant which appear in Equation (29) can be determined by prescribing the boundary condition for the velocity field in Equation (5), thus obtaining,

$$
U_{s}^{*}(Y)=\frac{G r}{C^{2}\left(1-e^{-C}\right)\left(1-e^{v_{0}}\right)}\left[\begin{array}{c}
\left(1+\frac{1}{1-P r}\right)\left(e^{-C}-e^{v_{0}}-e^{v_{0} Y}\left(e^{-C}-1\right)-e^{-C Y}\left(1-e^{v_{0}}\right)\right)+ \\
\left(1-\theta_{0}\left(1-e^{-C}\right)\right)\left(C-\operatorname{Pr}\left(1-e^{v_{0}}\right)-C e^{v_{0} Y}+\left(1-e^{v_{0}}\right)(\operatorname{Pr}-C Y)\right)
\end{array}\right]
$$

Where $C_{3}=\frac{\left(1+\frac{1}{1-P r}\right)\left(e^{-C}-e^{v_{0}}\right)+\left(1-\theta_{0}\left(1-e^{-C}\right)\right)\left(C-P r\left(1-e^{v_{0}}\right)\right)}{C^{2}\left(1-e^{-C}\right)\left(1-e^{v_{0}}\right)}, C_{4}=-G r \frac{\left[\left(1+\frac{1}{1-P r}\right)\left(e^{-C}-1\right)+C\left(1-\theta_{0}\left(1-e^{-C}\right)\right)\right]}{C^{2}\left(1-e^{-C}\right)\left(1-e^{v_{0}}\right)}$ are the two arbitrary constant.

Plugging the Equation (14) in Equation (3) yields to, 


$$
\frac{\partial U^{*}}{\partial t^{*}}-C \frac{\partial U^{*}}{\partial Y}=\frac{\partial^{2} U^{*}}{\partial Y^{2}}+\operatorname{Pr} G r\left(-\theta_{0}+\frac{e^{C}}{1-e^{C}}\left(e^{-C Y}-1\right)+\frac{\sin t^{*}}{\cosh d} e^{\left(P_{1}^{2} t_{\max }-t^{*}\right)} \cosh d Y\right)
$$

With the following boundary condition for velocity profiles as,

$$
0 \leq y^{*} \leq 1, U_{u}^{*}\left(0, t^{*}\right)=0, U_{u}^{*}\left(1, t^{*}\right)=0, \frac{\partial U^{*}\left(1, t_{\max }\right)}{\partial Y}=U_{0} .
$$

Starting with the homogeneous part of Equation (31), one obtain

$$
\frac{d U^{* *}}{d t^{*}}-C \frac{\partial U^{*}}{\partial Y}-\frac{\partial^{2} U^{*}}{\partial Y^{2}}=0
$$

The separation is given by the complementary solution as,

$$
U_{c}^{*}\left(Y, t^{*}\right)=Y(Y) T\left(t^{*}\right)
$$

Leads with Equation (32) to the eigen value problem as,

$$
\frac{T^{\prime}}{T}=\operatorname{Pr} \frac{Y^{\prime \prime}}{Y}+C \frac{Y^{\prime}}{Y}=-P_{2}^{2} \text { for } P_{2}>0
$$

The generalized complementary solution is of the form,

$$
U_{C}^{*}\left(Y, t^{*}\right)=e^{-\left(P_{2}^{2} t^{*}-\frac{1}{2} v_{0} Y\right)}\left(C_{5} \cos K Y+C_{6} \sin K Y\right)
$$

Using the boundary condition for unsteady velocity profiles one obtains,

$$
U_{C}^{*}\left(Y, t^{*}\right)=\frac{U_{0} \sin K Y e^{P 2}\left(\left(t_{\max }-t^{*}\right)-\frac{1}{2} v_{0}(1-Y)\right)}{K \cosh K-\frac{C}{2 P r} \sin K}
$$

Where, $C_{5}=0, C_{6}=\frac{U_{0} e^{\left(P_{2}^{2} t_{\max }-\frac{1}{2} v_{0}\right)}}{K \cosh K-\frac{C}{2 P r} \sin K}, K=\frac{\sqrt{C^{2}-4 P r P_{2}^{2}}}{2 P r}$

The particular solution for Equation (31) is given by,

$$
U_{P}^{*}\left(Y, t^{*}\right)=\frac{-\sin t^{*} e^{P_{1}^{2}\left(t_{\max }-t^{*}\right)}}{2 \cosh d}\left(\frac{e^{d Y}}{1+P_{1}^{2}+d C}+\frac{e^{d Y}}{1+P_{1}^{2}-d C}\right)-\theta_{0} t^{*}+C \theta_{0} Y+\frac{\operatorname{Pr} Y^{2} \theta_{0}}{2}+\frac{e^{C}}{1-e^{C}}\left(t^{*}-C Y-\frac{\operatorname{Pr} Y^{2}}{2}\right)
$$

The generalized solution of unsteady velocity profiles is of the form,

$$
U_{u}^{*}\left(Y, t^{*}\right)=U_{C}^{*}\left(y^{*}, t^{*}\right)+U_{P}^{*}\left(y^{*}, t^{*}\right)
$$

This yield to,

$$
\begin{gathered}
U_{u}^{*}\left(Y, t^{*}\right)=\frac{U_{0} \sin K Y e^{P_{2}^{2}\left(\left(t_{\max }-t^{*}\right)-\frac{1}{2} v_{0}(1-Y)\right)}}{K \cosh K-\frac{C}{2 P r} \sin K}-\frac{\sin t^{*} e^{P_{1}^{2}\left(t_{\max }-t^{*}\right)}}{2 \cosh d}\left(\frac{e^{d Y}}{1+P_{1}^{2}+d C}+\frac{e^{d Y}}{1+P_{1}^{2}-d C}\right)- \\
\theta_{0} t^{*}+C \theta_{0} Y+\frac{P r Y^{2} \theta_{0}}{2}+\frac{e^{C}}{1-e^{C}}\left(t^{*}-C Y-\frac{P r Y^{2}}{2}\right)
\end{gathered}
$$

The time dependent solution for the velocity field in Equation (31),

$$
U^{*}\left(Y, t^{*}\right)=U_{s}^{*}\left(Y, t^{*}\right)+U_{u}^{*}\left(Y, t^{*}\right)
$$

Therefore, the general time dependent solution for dimensionless velocity profiles is given by,

$$
U^{*}\left(Y, t^{*}\right)=\frac{G r}{C^{2}\left(1-e^{-C}\right)\left(1-e^{v_{0}}\right)}\left[\begin{array}{c}
\left(1+\frac{1}{1-P r}\right)\left(e^{-C}-e^{v_{0}}-e^{v_{0} Y}\left(e^{-C}-1\right)-e^{-C Y}\left(1-e^{v_{0}}\right)\right) \\
+\left(1-\theta_{0}\left(1-e^{-C}\right)\right)\left(C-\operatorname{Pr}\left(1-e^{v_{0}}\right)-C e^{v_{0} Y}+\left(1-e^{v_{0}}\right)(\operatorname{Pr}-C Y)\right)
\end{array}\right]
$$




$$
\begin{gathered}
+\frac{U_{0} \sin K Y e^{P_{2}^{2}\left(\left(t_{\max }-t^{*}\right)-\frac{1}{2} v_{0}(1-Y)\right)}}{K \cosh K-\frac{C}{2 P r} \sin K}-\frac{\sin t^{*} e^{P_{1}^{2}\left(t_{\max }-t^{*}\right)}}{2 \cosh d}\left(\frac{e^{d Y}}{1+P_{1}^{2}+d C}+\frac{e^{-d Y}}{1+P_{1}^{2}-d C}\right)-\theta_{0} t^{*}+C \theta_{0} Y+\frac{\operatorname{Pr} Y^{2} \theta_{0}}{2} \\
+\frac{e^{C}}{1-e^{C}}\left(t^{*}-C Y-\frac{P r Y^{2}}{2}\right)
\end{gathered}
$$

The volumetric airflow is defined in Equation (40) below,

$$
Q^{*}\left(Y, t^{*}\right)=A^{*} c_{d} \int_{s=0}^{s=\frac{Y}{2}} U^{*}\left(s, t^{*}\right) d s d t^{*}
$$

Putting Equation (39) in (40), one obtains

$$
\begin{gathered}
Q^{*}\left(Y, t^{*}\right)=A_{T} c_{d} \int_{s=0}^{s=\frac{Y}{2}}\left[\frac { G r } { C ^ { 2 } ( 1 - e ^ { - C } ) ( 1 - e ^ { v _ { 0 } ) } } \left[\left(1+\frac{1}{1-P r}\right)\left(e^{-C}-e^{v_{0}}-e^{v_{0} s}\left(e^{-C}-1\right)-e^{-C s}\left(1-e^{v_{0}}\right)\right)+\left(1-\theta_{0}(1-\right.\right.\right. \\
\left.\left.\left.e^{-C}\right)\right)\left(C-P r\left(1-e^{v_{0}}\right)-C e^{v_{0} s}+\left(1-e^{v_{0}}\right)(P r-C s)\right)\right]+\frac{\left.U_{0} \sin K s e^{P_{2}^{2}\left(\left(t_{\max }-t^{*}\right)-\frac{1}{2} v_{0}(1-s)\right.}\right)}{K \cosh K-\frac{C}{2 P r} \sin K}-\frac{\sin ^{*} e^{P_{1}^{2}\left(t_{\max }-t^{*}\right)}}{2 \cosh d}\left(\frac{e^{d s}}{1+P_{1}^{2}+d C}+\right. \\
\left.\left.\frac{e^{-d s}}{1+P_{1}^{2}-d C}\right)-\theta_{0} t^{*}+C \theta_{0} s+\frac{P r s^{2} \theta_{0}}{2}+\frac{e^{C}}{1-e^{C}}\left(t^{*}-C s-\frac{P r s^{2}}{2}\right)\right] d s d t^{*}
\end{gathered}
$$

Where, $s$ is a dummy variable.

The results for Equation (41) yields to volumetric airflow as,.

$$
\begin{aligned}
& Q^{*}\left(Y, t^{*}\right)=A_{T} c_{d}\left[\frac{G r}{C^{2}\left(1-e^{-C}\right)\left(1-e^{\left.v_{0}\right)}\right.}\left(\left(1+\frac{1}{1-P r}\right)\left(\left(e^{-C}-e^{v_{0}}\right) \frac{Y}{2}\right)-\left(e^{-C}-1\right) \frac{e^{v_{0} \frac{Y}{2}}}{v_{0}}+\left(1-e^{v_{0}}\right) \frac{e^{C \frac{Y}{2}}}{C}+\frac{\left(e^{-C}-1\right)}{v_{0}}-\frac{\left(1-e^{v_{0}}\right)}{C}\right)+\right. \\
& \begin{array}{c}
\left(1-\theta_{0}\left(1-e^{-C}\right)\right)\left(-\operatorname{Pr}\left(v_{0}+\left(1-e^{v_{0}}\right)\right) \frac{Y}{2}+\operatorname{Pr} e^{v_{0} \frac{Y}{2}}+\left(1-e^{v_{0}}\right)\left(\operatorname{Pr} \frac{Y}{2}-C \frac{Y^{2}}{8}\right)-\operatorname{Pr}\right) t^{*}+ \\
\frac{\left.\frac{U_{0} v_{0}}{2} e^{P_{2}^{2}\left(\left(t_{\max }-t^{*}\right)+\frac{1}{2} v_{0}\right.}\right)\left(\left(\sinh K \frac{Y}{2}+K^{2} P_{2}^{2} \frac{v_{0}}{2} \cosh K \frac{Y}{2}\right) e^{-v_{0} \frac{Y}{4}}-K P_{2}^{2} \frac{v_{0}}{2}\right)}{\left(K \cosh K+\frac{1}{2} v_{0} \sinh K\right)\left(1-K^{2}\left(P_{2}^{2} \frac{v_{0}}{2}\right)^{2}\right)}+\frac{\left(\frac{\cos t^{*}}{P_{1}^{2}}-\sin t^{*}\right) e^{P_{1}^{2}\left(t_{\max }-t^{*}\right)}}{2 b \operatorname{coshd} P_{1}^{2}\left(1-\frac{1}{\left(P_{1}^{2}\right)^{2}}\right)}\left(\frac{1-e^{d \frac{Y}{2}}}{1+P_{1}^{2}+d C}+\frac{e^{-d \frac{Y}{2}}-1}{1+P_{1}^{2}-d C}\right)-\theta_{0} t^{2} \frac{Y}{4}+
\end{array} \\
& \left.\left(C \theta_{0} \frac{Y^{2}}{8}+\operatorname{Pr} \theta_{0} \frac{Y^{3}}{48}\right) t^{*}+\frac{e^{C}}{1-e^{C}}\left(t^{* 2} \frac{Y}{4}-C \frac{Y^{2}}{8} t^{*}-\operatorname{Pr} \frac{Y^{3}}{48} t^{*}\right)\right]
\end{aligned}
$$

The mass transfer is given by Equation (43) below as,

$$
m^{*}\left(Y, t^{*}\right)=\rho_{a} Q^{*}\left(Y, t^{*}\right)
$$

By plugging Equation (42) in (43), one obtains mass transfer as,

$$
\begin{gathered}
m^{*}\left(Y, t^{*}\right)=A_{T} \rho_{a} c_{d}\left[\frac{G r}{C^{2}\left(1-e^{-C}\right)\left(1-e^{\left.v_{0}\right)}\right.}\left(\left(1+\frac{1}{1-P r}\right)\left(\left(e^{-C}-e^{v_{0}}\right) \frac{Y}{2}\right)-\left(e^{-C}-1\right) \frac{e^{v_{0} \frac{Y}{2}}}{v_{0}}+\left(1-e^{v_{0}}\right) \frac{e^{c \frac{Y}{2}}}{C}+\frac{\left(e^{-C}-1\right)}{v_{0}}-\frac{\left(1-e^{v_{0}}\right)}{C}\right)+\right. \\
\left(1-\theta_{0}\left(1-e^{-C}\right)\right)\left(-\operatorname{Pr}\left(v_{0}+\left(1-e^{v_{0}}\right)\right) \frac{Y}{2}+\operatorname{Pr} e^{v_{0} \frac{Y}{2}}+\left(1-e^{v_{0}}\right)\left(\operatorname{Pr} \frac{Y}{2}-C \frac{Y^{2}}{8}\right)-\operatorname{Pr}\right) t^{*}+ \\
\frac{\left.\frac{U_{0} v_{0}}{2} e^{P_{2}^{2}\left(\left(t_{\max }-t^{*}\right)+\frac{1}{2} v_{0}\right.}\right)\left(\left(\sinh K \frac{Y}{2}+K^{2} P_{2}^{2} \frac{v_{0}}{2} \cosh K \frac{Y}{2}\right) e^{-v_{0} \frac{Y}{4}-K P_{2}^{2} \frac{v_{0}}{2}}\right)}{\left(K \cosh K+\frac{1}{2} v_{0} \sinh K\right)\left(1-K^{2}\left(P_{2}^{2} \frac{v_{0}}{2}\right)^{2}\right)}+\frac{\left(\frac{\cos t^{*}}{P_{1}^{2}}-\sin t^{*}\right) e^{P_{1}^{2}\left(t_{\max }-t^{*}\right)}}{2 b \cosh P_{1}^{2}\left(1-\frac{1}{\left(P_{1}^{2}\right)^{2}}\right)}\left(\frac{1-e^{d \frac{Y}{2}}}{1+P_{1}^{2}+d C}+\frac{e^{-d \frac{Y}{2}}-1}{1+P_{1}^{2}-d C}\right)-\theta_{0} t^{* 2} \frac{Y}{4}+\left(C \theta_{0} \frac{Y^{2}}{8}+\right. \\
\left.\left.\operatorname{Pr} \theta_{0} \frac{Y^{3}}{48}\right) t^{*}+\frac{e^{C}}{1-e^{C}}\left(t^{* 2} \frac{Y}{4}-C \frac{Y^{2}}{8} t^{*}-\operatorname{Pr} \frac{Y^{3}}{48} t^{*}\right)\right]
\end{gathered}
$$




\section{Numerical Examples}

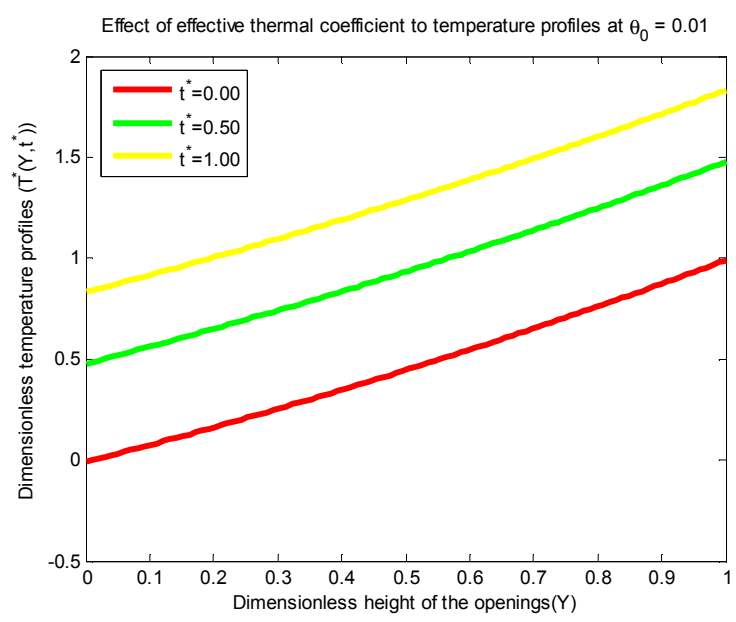

Figure 4. Transient temperature profiles $T^{*}$ versus $y^{*}$ and $t^{*}$ for $\theta_{0}=0.01$ with fixed value of $\mathrm{Pr}=0.710$.

In this section the main features of the solutions found in the previous section (4.0) will be discussed. This is done in order to see the effect of changes of parameters to the overall distributions, while keeping other operating conditions and parameters fixed, and ascertain the best one for optimal natural ventilation. The non- dimensional Equations in (8) (9) are solved analytically with the separation of variables method and the solutions for temperature, velocity profiles together with volumetric airflow and mass transfer are expressed in Equations (22), (39), (42) and (44) and distributions plotted. The solutions obtained for temperature, velocity profiles together with volumetric airflow and mass transfer are governed by effective thermal coefficient $\left(\theta_{0}\right)$, Prandtl number $(P r)$ and Grashof number $(G r)$. To examine the effects of different parameters governing the convective flow, the values of Prandtl number $(P r)$ is chosen to be $\operatorname{Pr}=0.71$ corresponding to air, the values of Grashof number $(G r)$ is chosen for cooling case $(G r>0)$, a case of general interest in energy system technologies.

The remaining parameters are chosen arbitrarily.

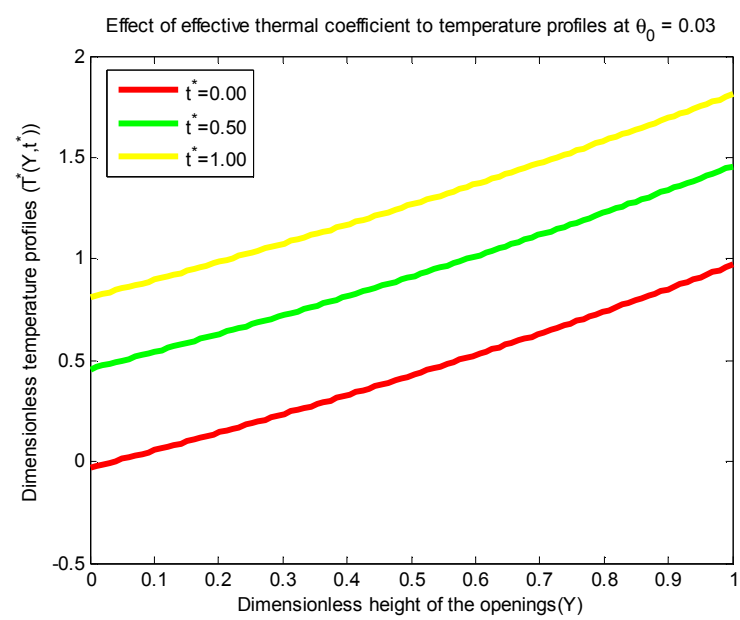

Figure 5. Transient temperature profiles $T^{*}$ versus $y^{*}$ and $t^{*}$ for $\theta_{0}=0.03$ with fixed value of $\mathrm{Pr}=0.710$.

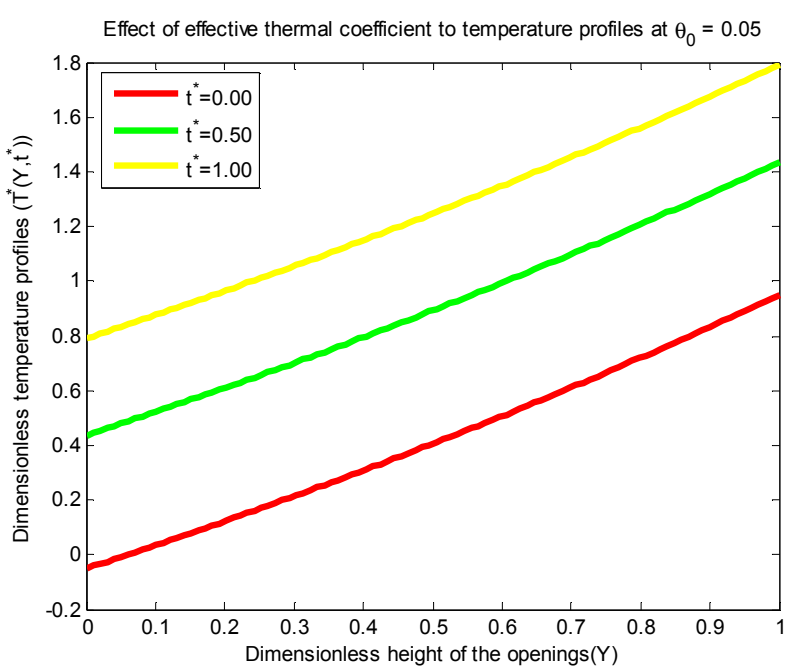

Figure 6. Transient temperature profiles $T^{*}$ versus $y^{*}$ and $t^{*}$ for $\theta_{0}=0.05$ with fixed value of $\mathrm{Pr}=0.710$.

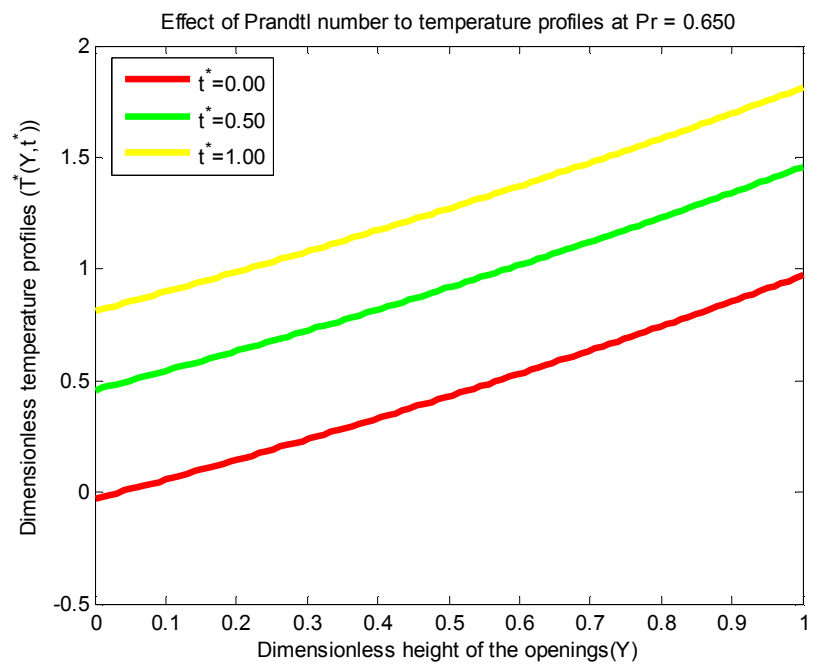

Figure 7. Transient temperature profiles $T^{*}$ versus $y^{*}$ and $t^{*}$ for $\operatorname{Pr}=0.650$ with fixed value of $\theta_{0}=0.03$.

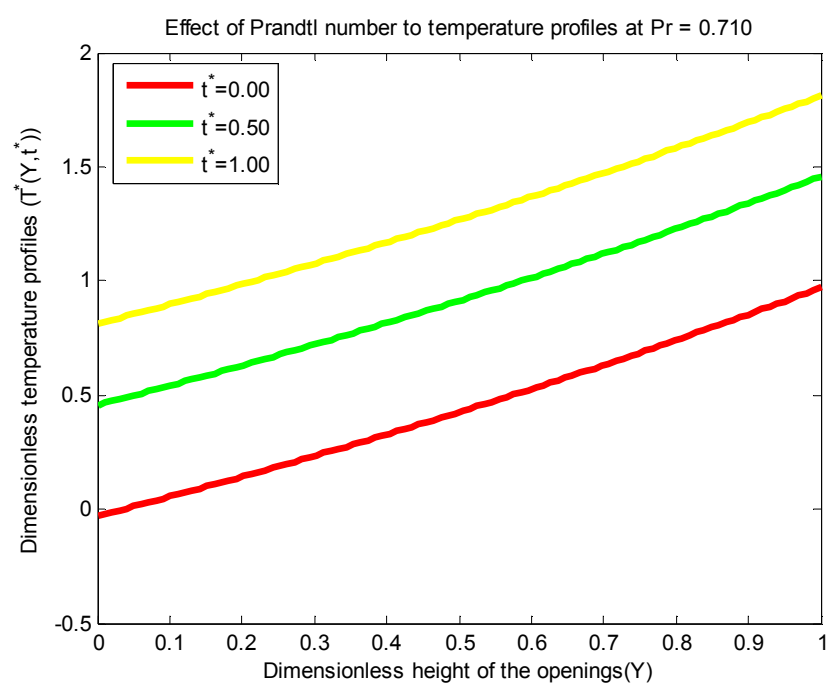

Figure 8. Transient temperature profiles $T^{*}$ versus $y^{*}$ and $t^{*}$ for $\operatorname{Pr}=0.710$ with fixed value of $\theta_{0}=0.03$. 


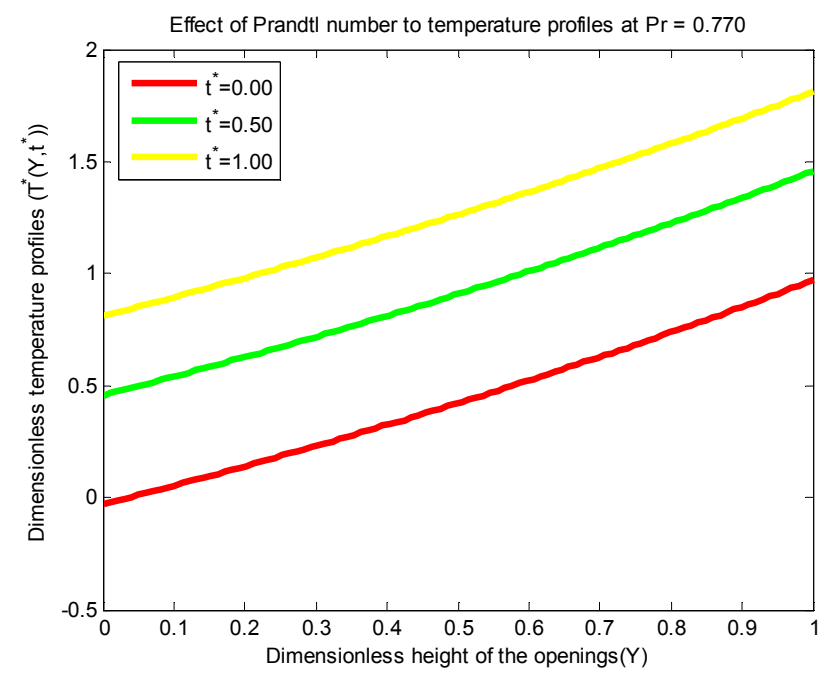

Figure 9. Transient temperature profiles $T^{*}$ versus $y^{*}$ and $t^{*}$ for $\operatorname{Pr}=0.770$ with fixed value of $\theta_{0}=0.03$.

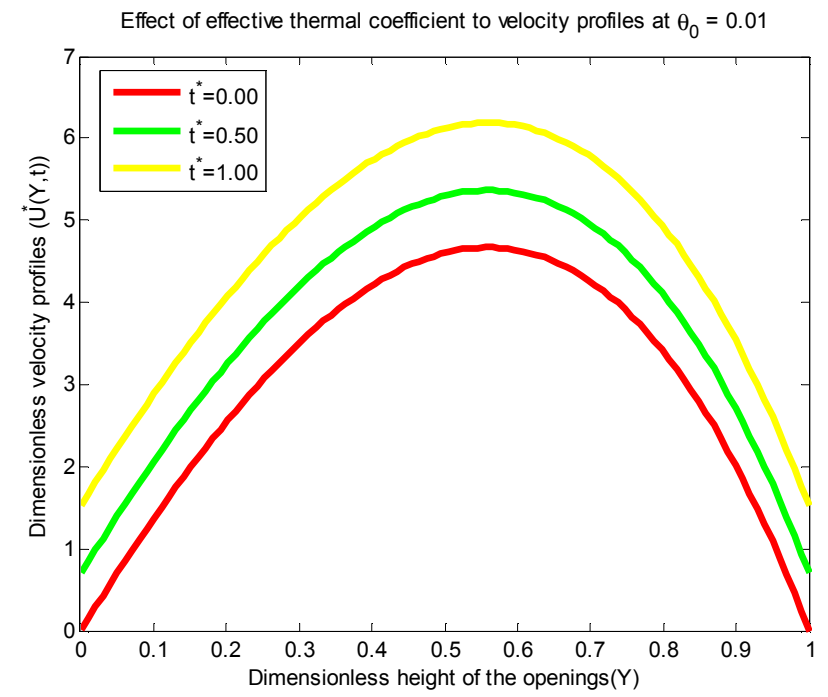

Figure 10. Transient velocity profiles $U^{*}$ versus $y^{*}$ and $t^{*}$ for $\theta_{0}=0.01$ with fixed value of $\mathrm{Pr}=0.710$ and $\mathrm{Gr}=20$.

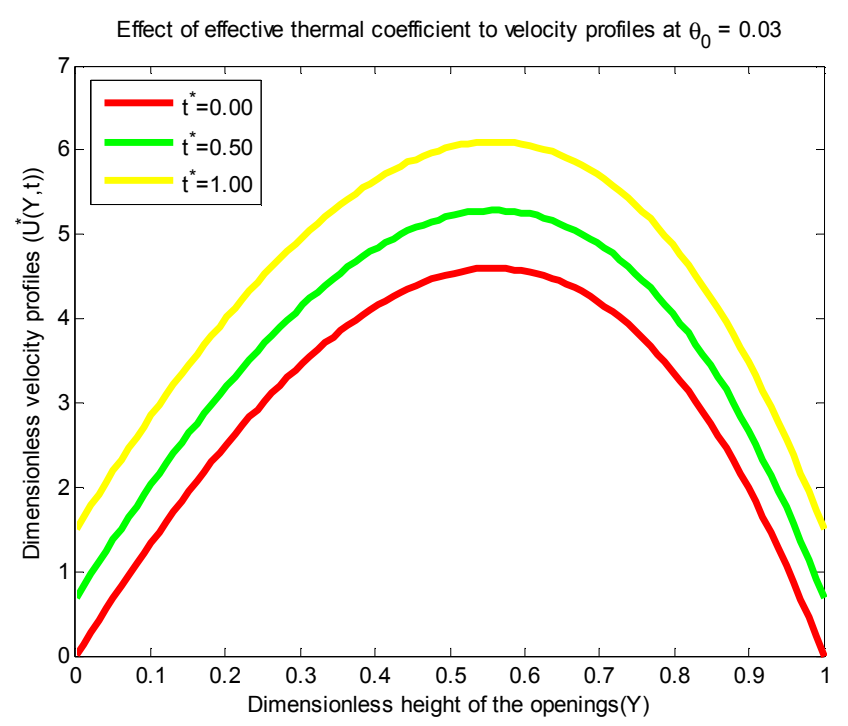

Figure 11. Transient velocity profiles $U^{*}$ versus $y^{*}$ and $t^{*}$ for $\theta_{0}=0.03$ with fixed value of $\mathrm{Pr}=0.710$ and $\mathrm{Gr}=20$.

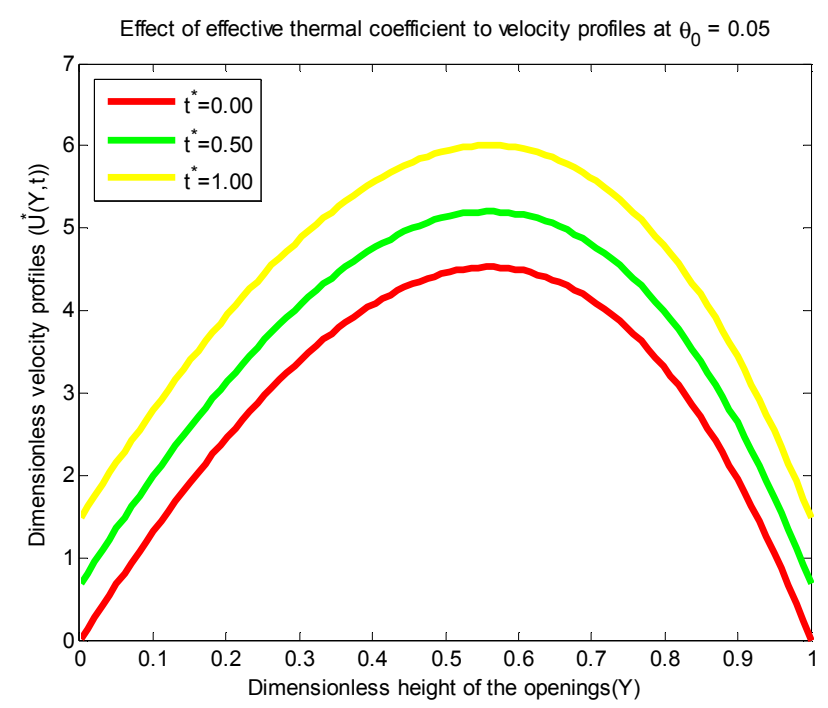

Figure 12. Transient velocity profiles $U^{*}$ versus $y^{*}$ and $t^{*}$ for $\theta_{0}=0.05$ with fixed value of $\mathrm{Pr}=0.710$ and $\mathrm{Gr}=20$.

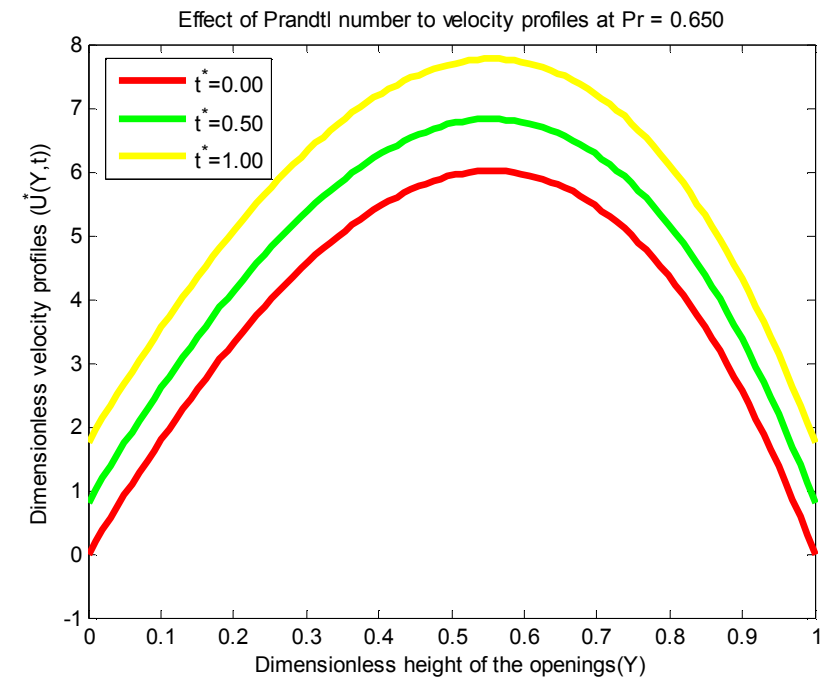

Figure 13. Transient velocity profiles $U^{*}$ versus $y^{*}$ and $t^{*}$ for $\operatorname{Pr}=0.650$ with fixed value of $\theta_{0}=0.03$ and $G r=20$.

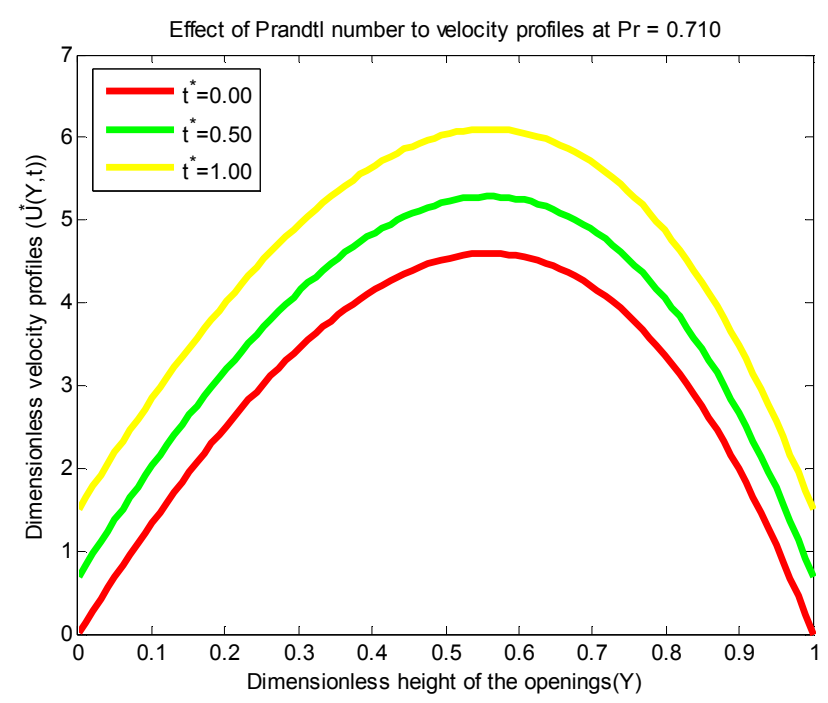

Figure 14. Transient velocity profiles $U^{*}$ versus $y^{*}$ and $t^{*}$ for $\operatorname{Pr}=0.710$ with fixed value of $\theta_{0}=0.03$ and $G r=20$. 


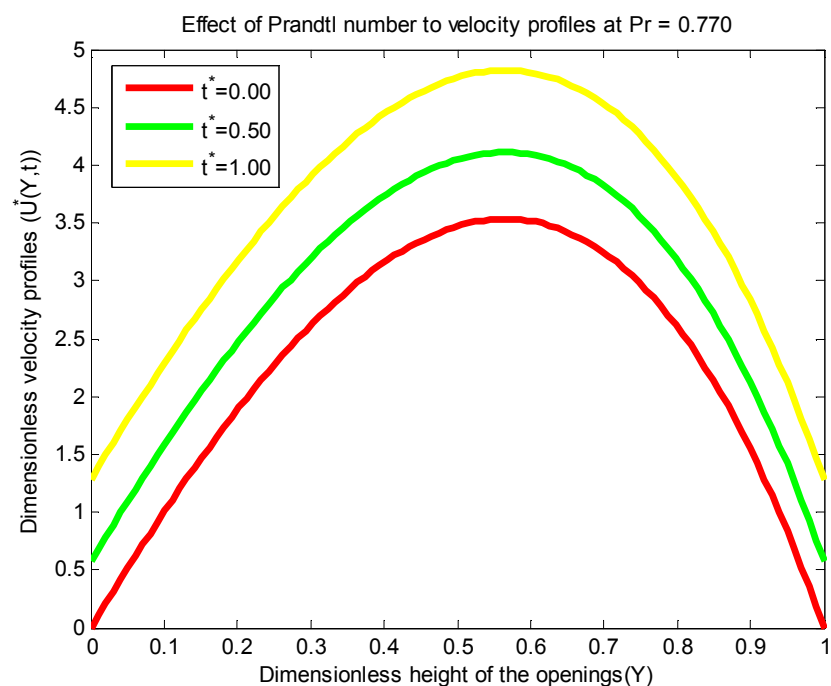

Figure 15. Transient velocity profiles $U^{*}$ versus $y^{*}$ and $t^{*}$ for $\operatorname{Pr}=0.770$ with fixed value of $\theta_{0}=0.03$ and $G r=20$.

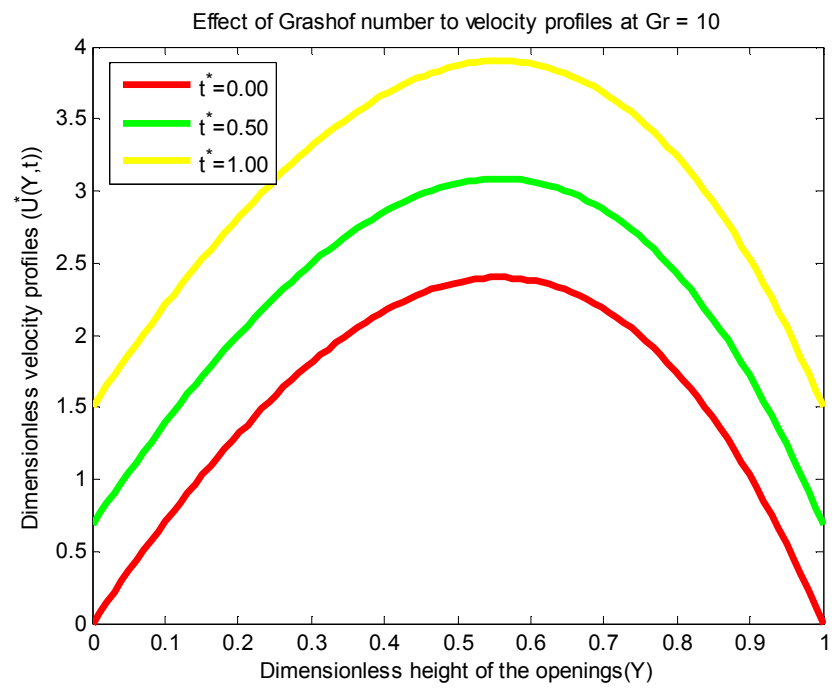

Figure 16. Transient velocity profiles $U^{*}$ versus $y^{*}$ and $t^{*}$ for $\mathrm{Gr}=10$ with fixed value of $\operatorname{Pr}=0.710$ and $\theta_{0}=0.03$.

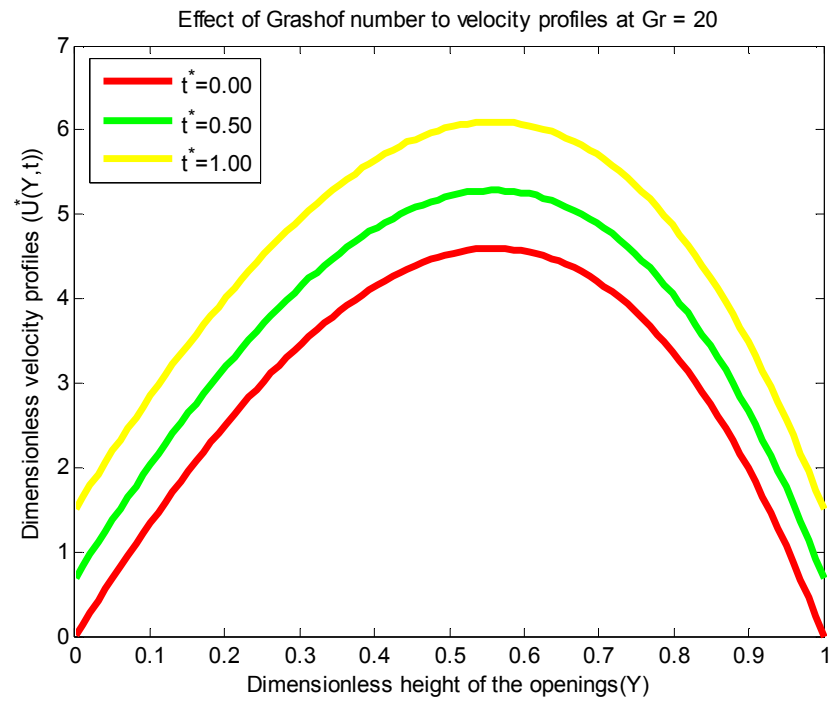

Figure 17. Transient velocity profiles $U^{*}$ versus $y^{*}$ and $t^{*}$ for $\mathrm{Gr}=20$ with fixed value of $\operatorname{Pr}=0.710$ and $\theta_{0}=0.03$.

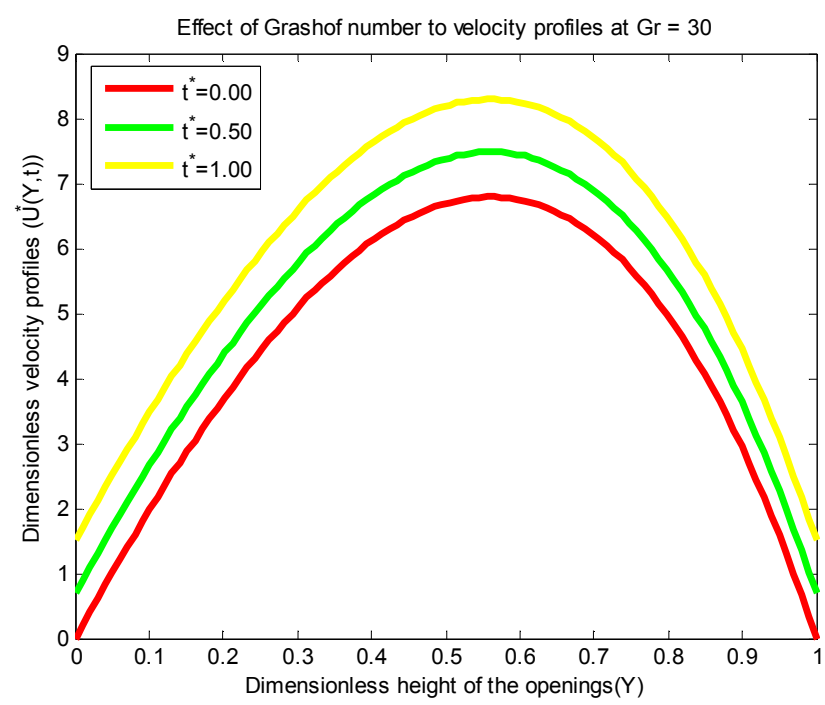

Figure 18. Transient velocity profiles $U^{*}$ versus $y^{*}$ and $t^{*}$ for $G r=30$ with fixed value of $\operatorname{Pr}=0.710$ and $\theta_{0}=0.03$.

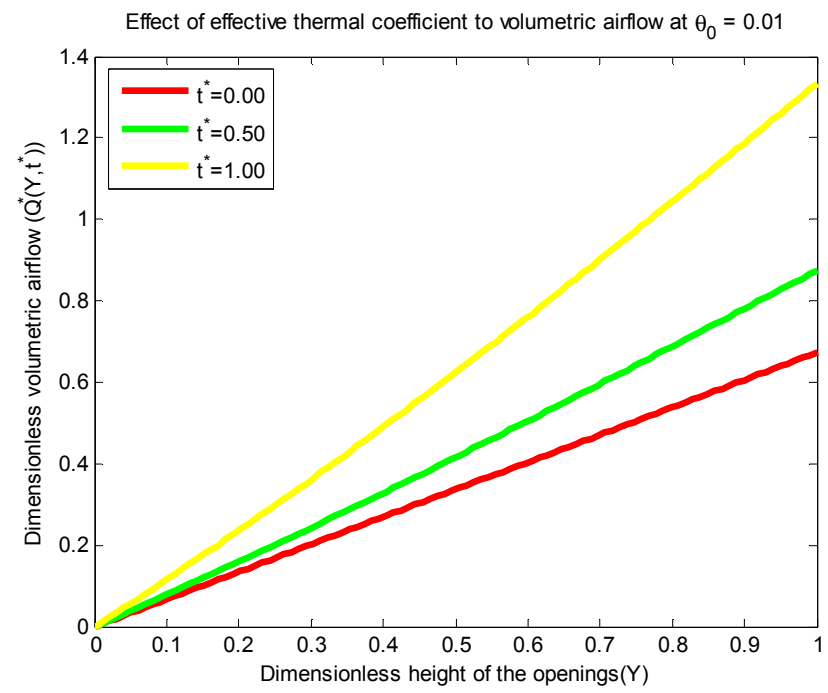

Figure 19. Transient volumetric airflow $Q^{*}$ versus $y^{*}$ and $t^{*}$ for $\theta_{0}=0.01$ with fixed value of $\mathrm{Pr}=0.710$ and $\mathrm{Gr}=20$.

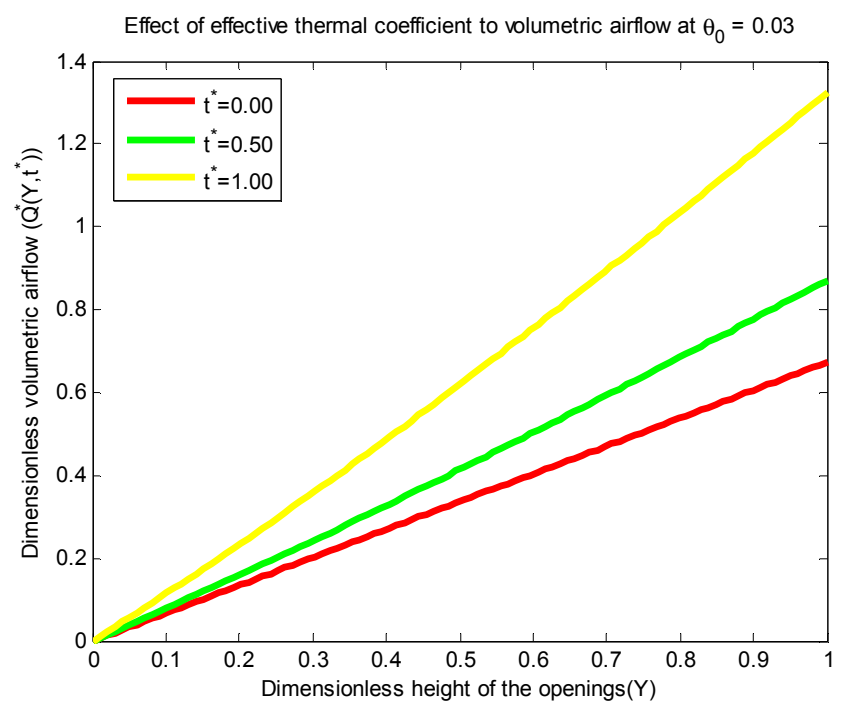

Figure 20. Transient volumetric airflow $Q^{*}$ versus $y^{*}$ and $t^{*}$ for $\theta_{0}=0.03$ with fixed value of $\mathrm{Pr}=0.710$ and $\mathrm{Gr}=20$. 


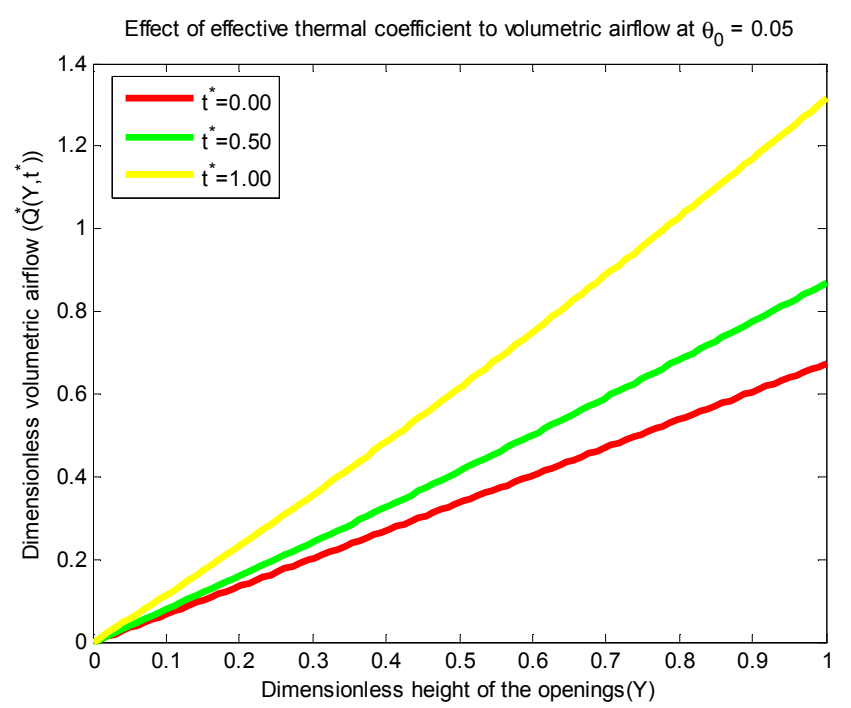

Figure 21. Transient volumetric airflow $Q^{*}$ versus $y^{*}$ and $t^{*}$ for $\theta_{0}=0.05$ with fixed value of $\mathrm{Pr}=0.710$ and $\mathrm{Gr}=20$.

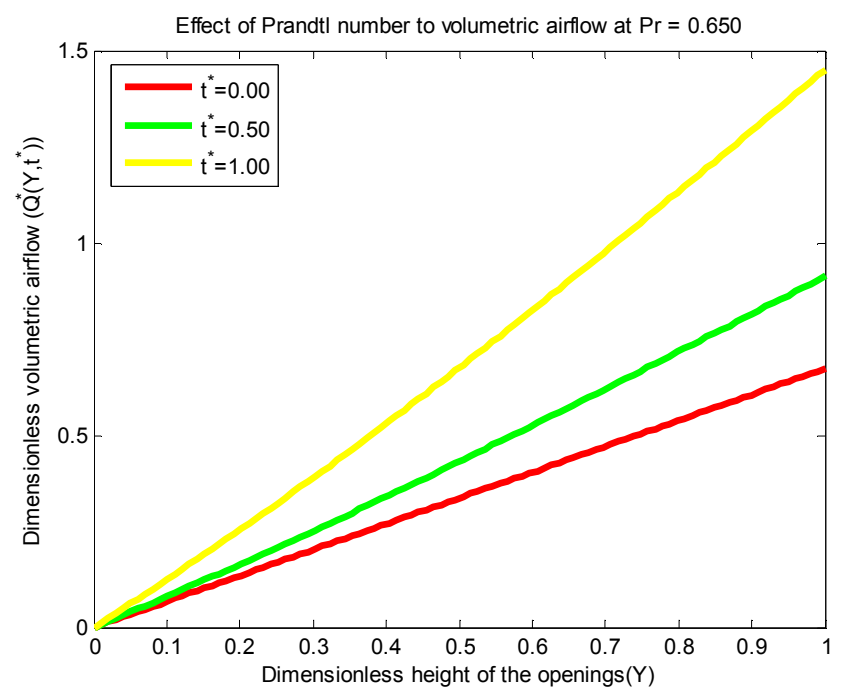

Figure 22. Transient volumetric airflow $Q^{*}$ versus $y^{*}$ and $t^{*}$ for $\operatorname{Pr}=0.650$ with fixed value of $\theta_{0}=0.03$ and $G r=20$.

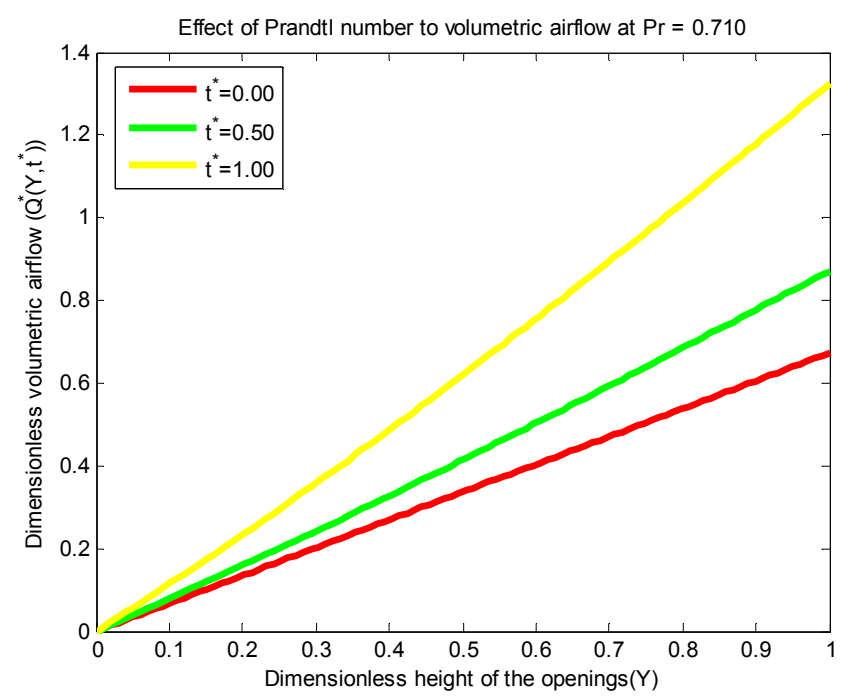

Figure 23. Transient volumetric airflow $Q^{*}$ versus $y^{*}$ and $t^{*}$ for $\operatorname{Pr}=0.710$ with fixed value of $\theta_{0}=0.03$ and $G r=20$.

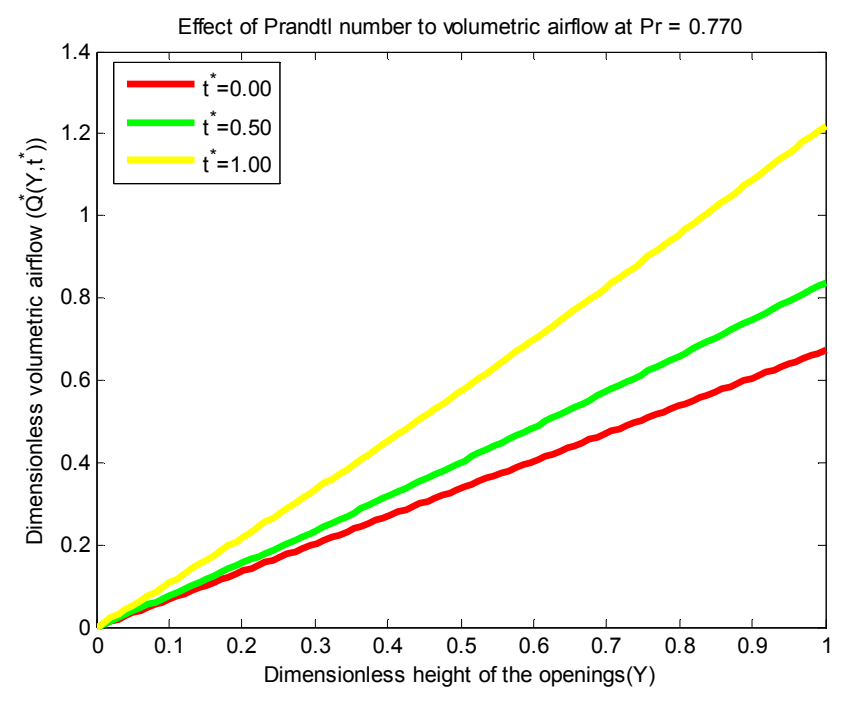

Figure 24. Transient volumetric airflow $Q^{*}$ versus $y^{*}$ and $t^{*}$ for $\operatorname{Pr}=0.770$ with fixed value of $\theta_{0}=0.03$ and $G r=20$.

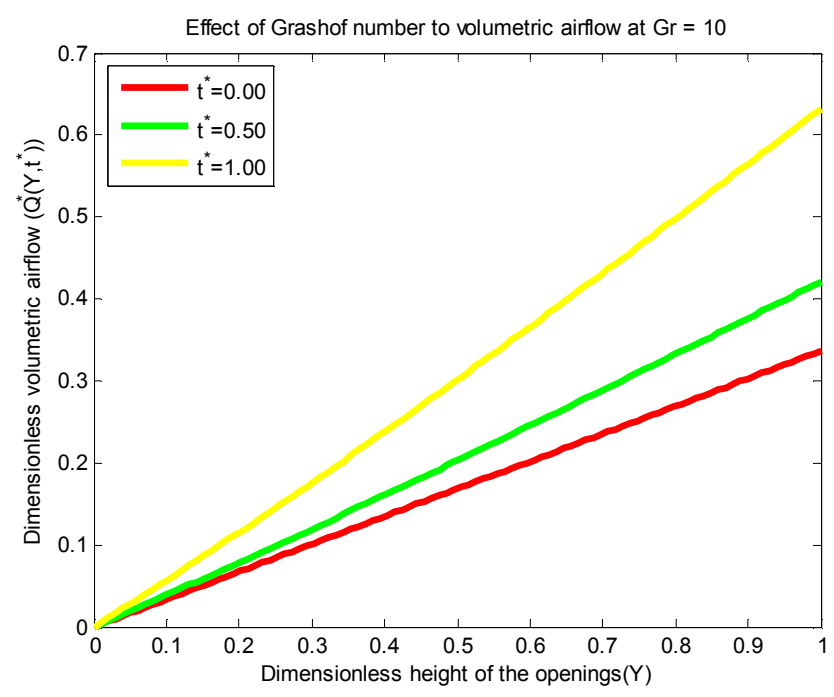

Figure 25. Transient volumetric airflow $Q^{*}$ versus $y^{*}$ and $t^{*}$ for $G r=10$ with fixed value of $\theta_{0}=0.03$ and $\operatorname{Pr}=0.710$.

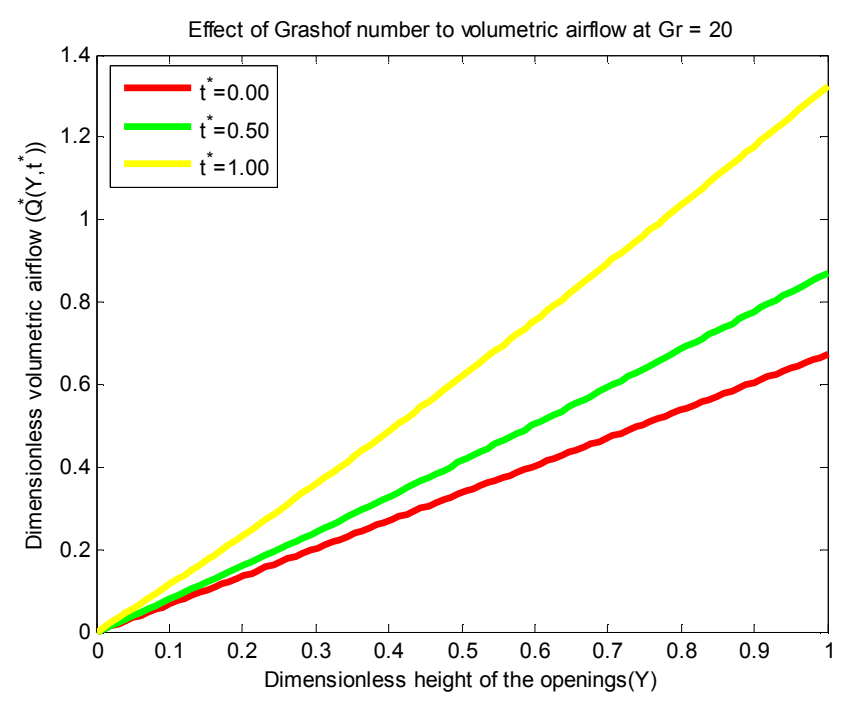

Figure 26. Transient volumetric airflow $Q^{*}$ versus $y^{*}$ and $t^{*}$ for $G r=20$ with fixed value of $\theta_{0}=0.03$ and $P r=0.710$. 
Muhammad Auwal Lawan and Sunusi Aminu Nata'ala: Transient Investigation of Stack-driven Air Flow Through Multiple Upper-vents in the Presence of Constant Indirect Flow Velocity in Rectangular Ventilated Building

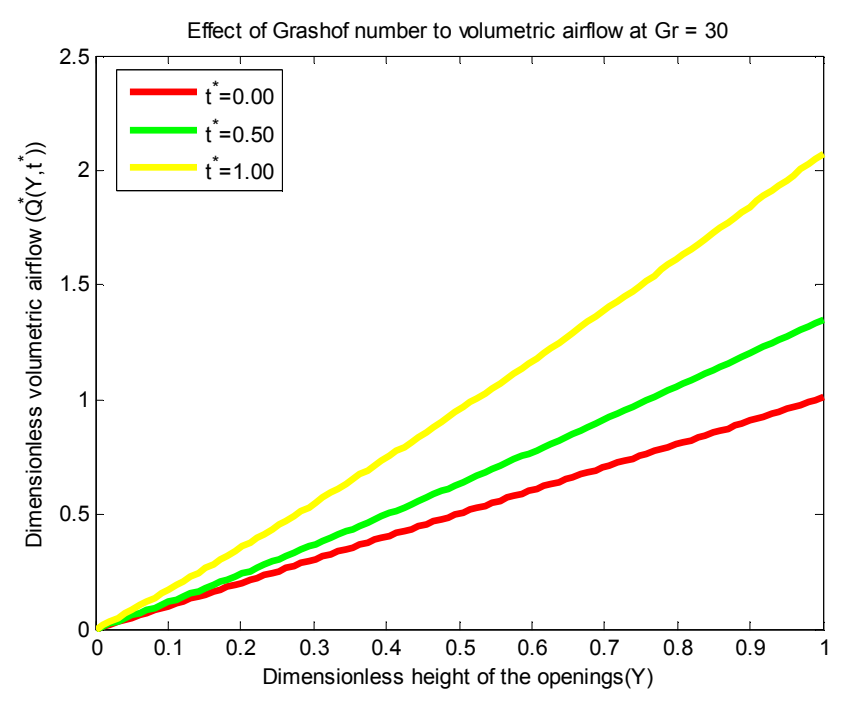

Figure 27. Transient volumetric airflow $Q^{*}$ versus $y^{*}$ and $t^{*}$ for $G r=30$ with fixed value of $\theta_{0}=0.03$ and $\mathrm{Pr}=0.710$.

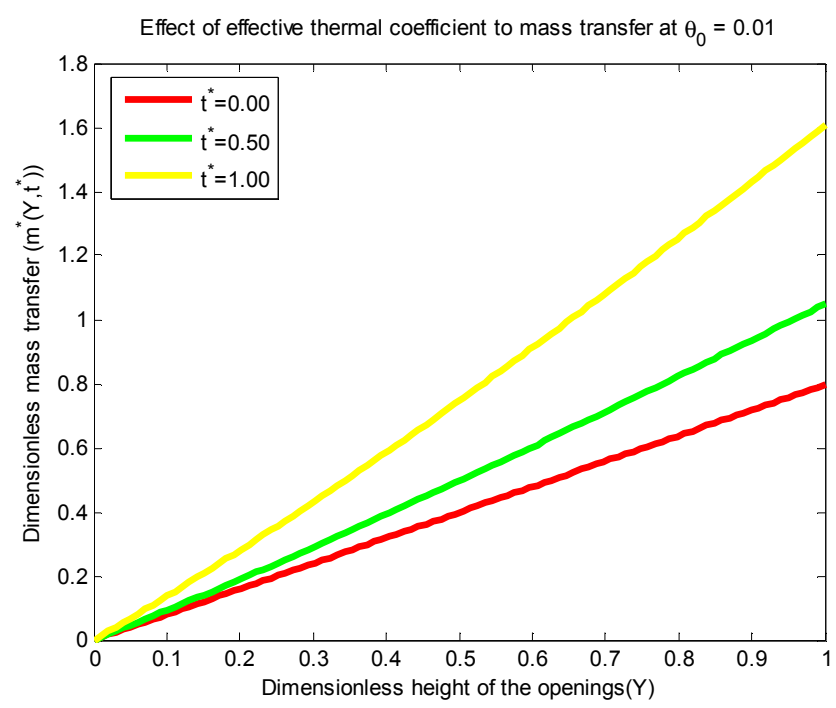

Figure 28. Transient mass transfer $m^{*}$ versus $y^{*}$ and $t^{*}$ for $\theta_{0}=0.01$ with fixed value of $\mathrm{Gr}=20$ and $\mathrm{Pr}=0.710$.

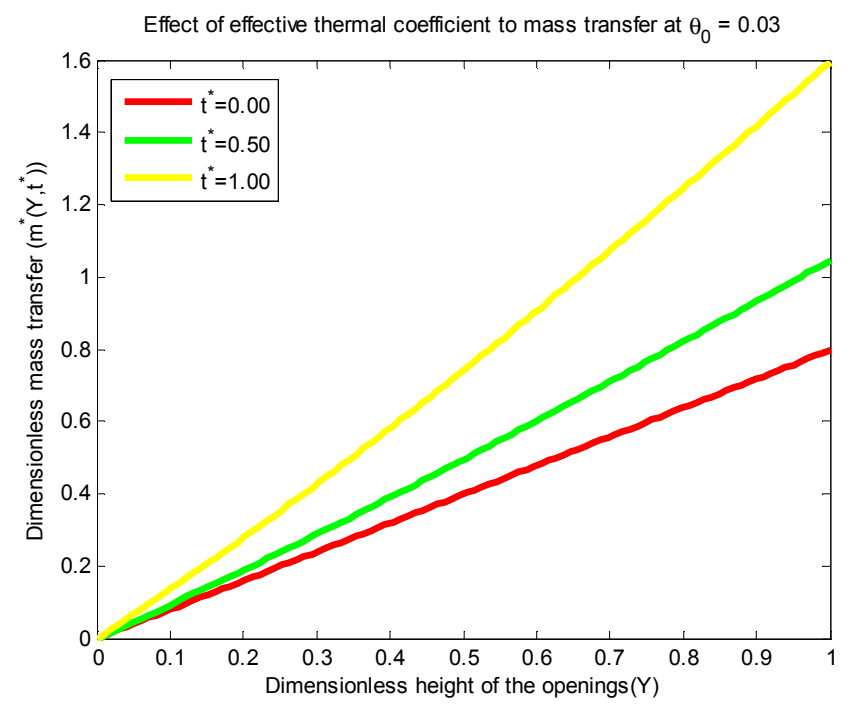

Figure 29. Transient mass transfer $m^{*}$ versus $y^{*}$ and $t^{*}$ for $\theta_{0}=0.03$ with fixed value of $\mathrm{Gr}=20$ and $\mathrm{Pr}=0.710$.

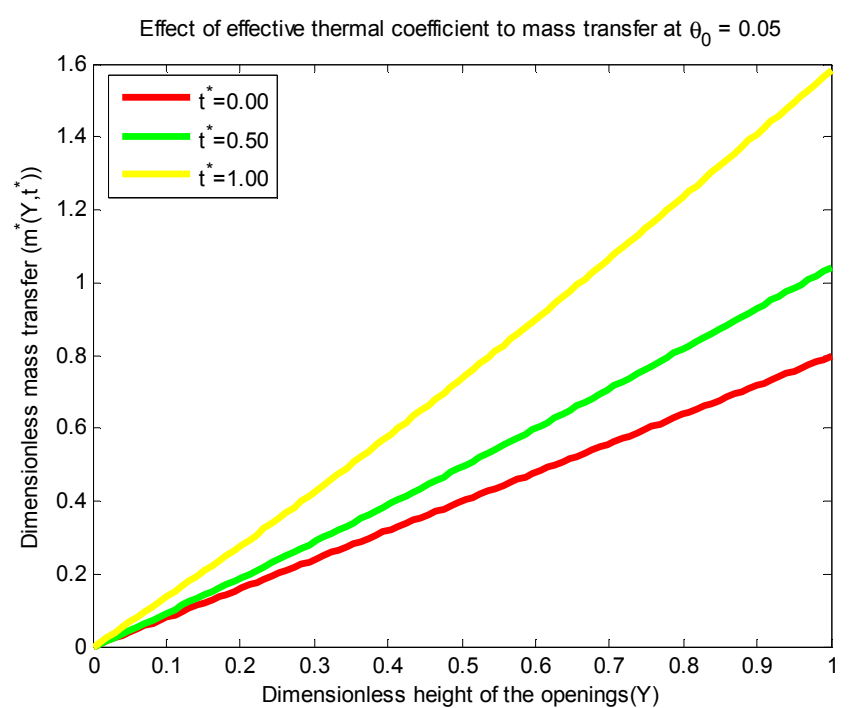

Figure 30. Transient mass transfer $m^{*}$ versus $y^{*}$ and $t^{*}$ for $\theta_{0}=0.05$ with fixed value of $G r=20$ and $\operatorname{Pr}=0.710$.

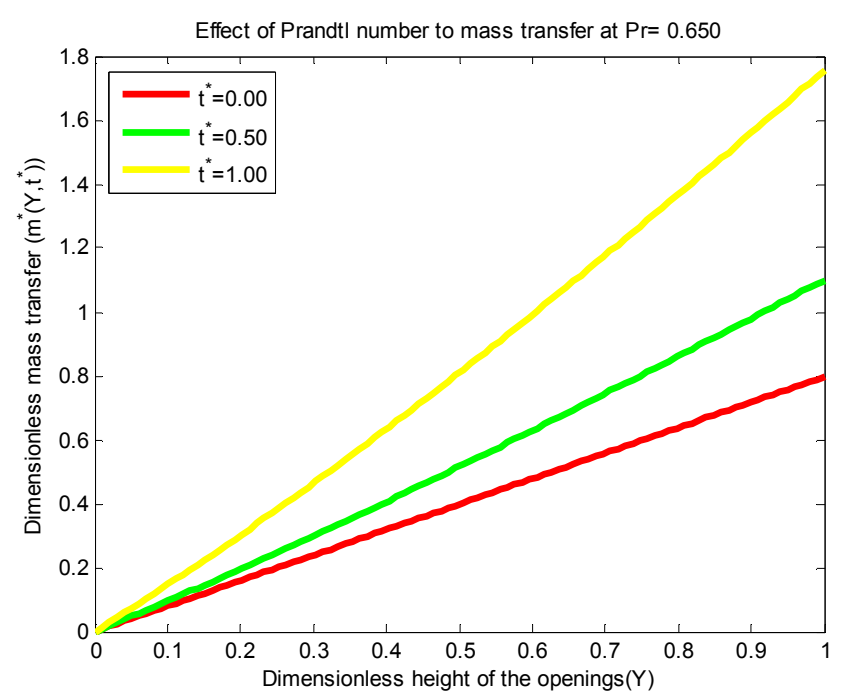

Figure 31. Transient mass transfer $m^{*}$ versus $y^{*}$ and $t^{*}$ for $\mathrm{Pr}=0.650$ with fixed value of $G r=20$ and $\theta_{0}=0.03$.

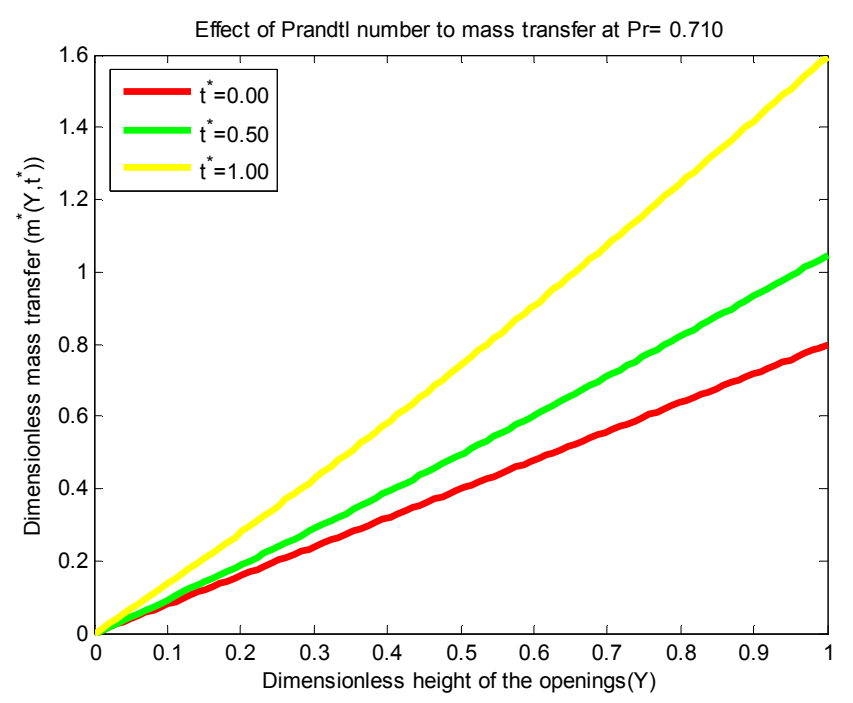

Figure 32. Transient mass transfer $m^{*}$ versus $y^{*}$ and $t^{*}$ for $\operatorname{Pr}=0.710$ with fixed value of $G r=20$ and $\theta_{0}=0.03$. 


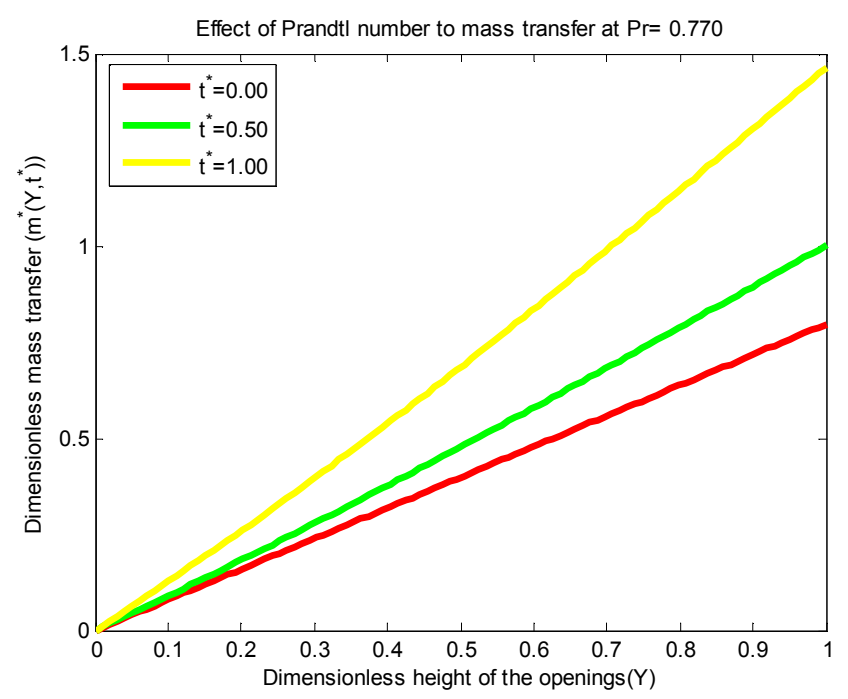

Figure 33. Transient mass transfer $m^{*}$ versus $y^{*}$ and $t^{*}$ for $\operatorname{Pr}=0.770$ with fixed value of $G r=20$ and $\theta_{0}=0.03$

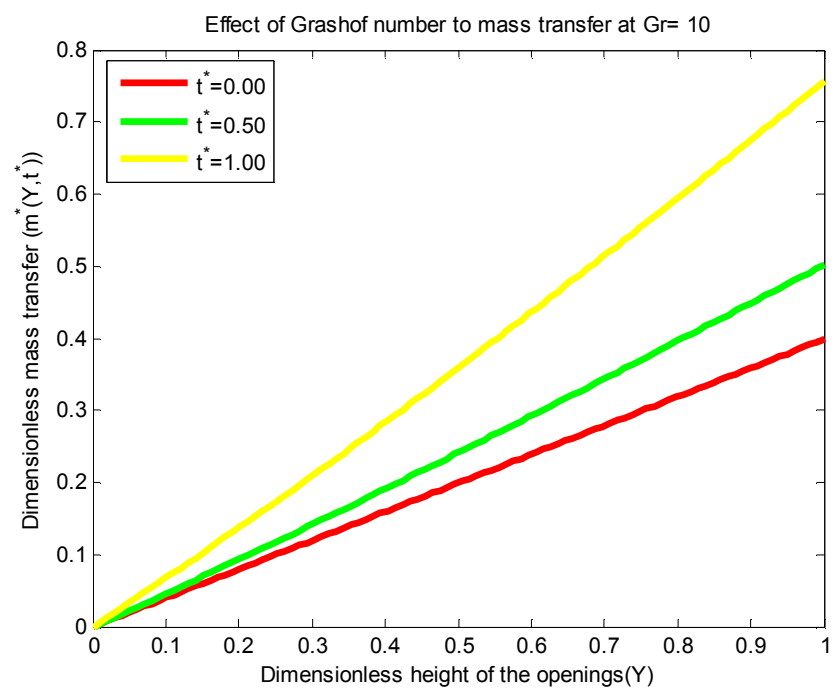

Figure 34. Transient mass transfer $m^{*}$ versus $y^{*}$ and $t^{*}$ for $G r=10$ with fixed value of $\operatorname{Pr}=0.710$ and $\theta_{0}=0.03$.

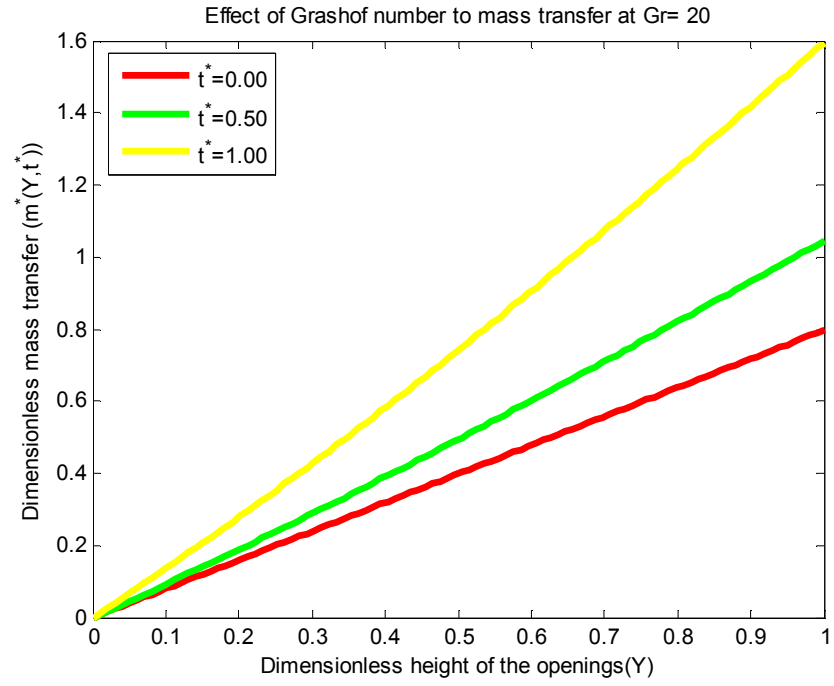

Figure 35. Transient mass transfer $m^{*}$ versus $y^{*}$ and $t^{*}$ for $G r=20$ with fixed value of $\operatorname{Pr}=0.710$ and $\theta_{0}=0.03$.

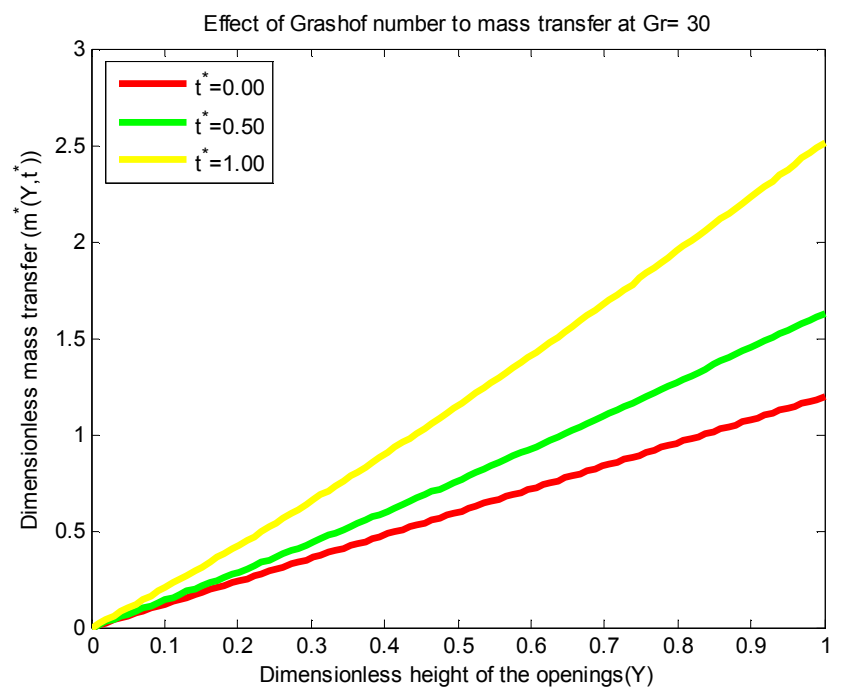

Figure 36. Transient mass transfer $m^{*}$ versus $y^{*}$ and $t^{*}$ for $G r=30$ with fixed value of $\operatorname{Pr}=0.710$ and $\theta_{0}=0.03$.

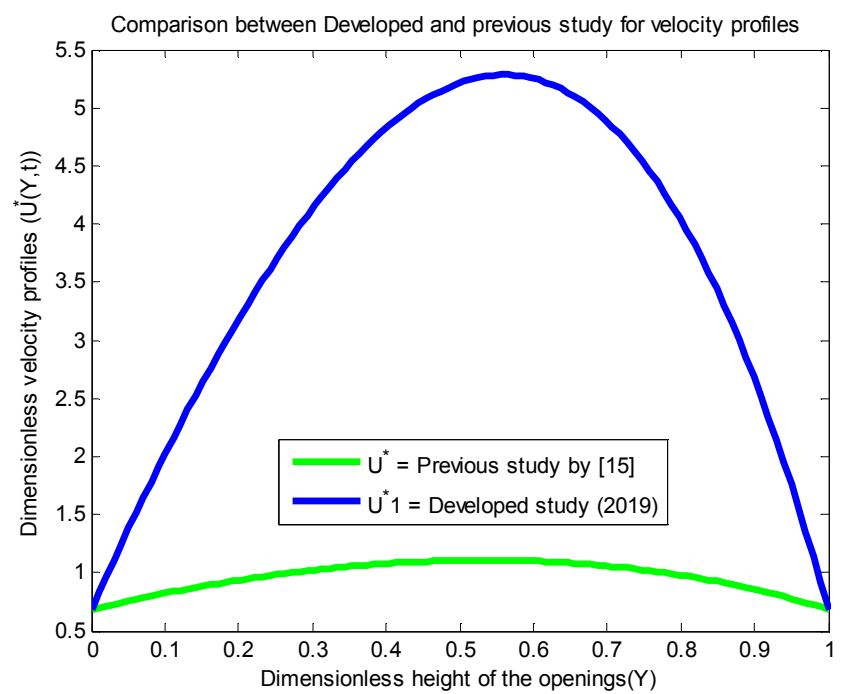

Figure 37. Comparison between velocity profiles $U^{*}$ and $U^{*} 1$ for fixed values of $\theta_{0}=0.03, \operatorname{Pr}=0.710$, and $G r=20$.

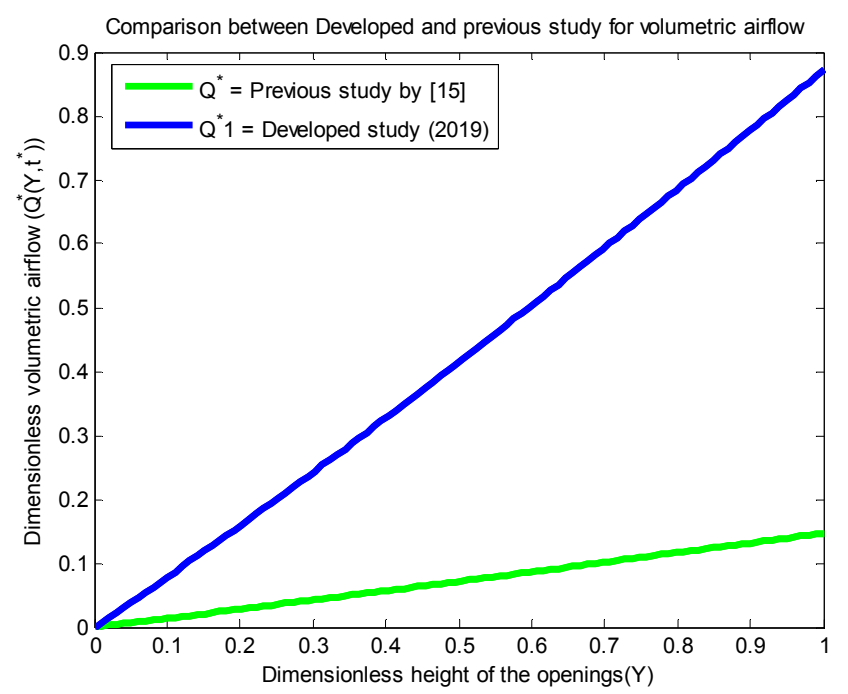

Figure 38. Comparison between volumetric airflow $Q^{*}$ and $Q^{*} 1$ for fixed values of $\theta_{0}=0.03, \operatorname{Pr}=0.710$, and $\mathrm{Gr}=20$. 


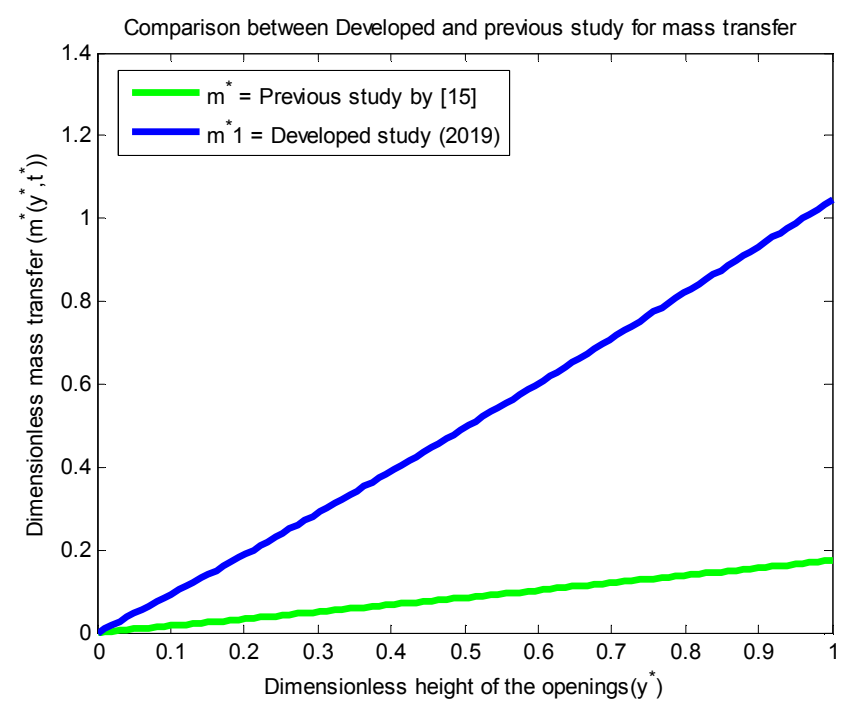

Figure 39. Comparison between mass transfer $m^{*}$ and $m^{*} 1$ for fixed values of $\theta_{0}=0.03, \operatorname{Pr}=0.710$, and $\mathrm{Gr}=20$.

A Physical interpretation of transient temperature profiles $\left(T^{*}\right)$ for three incremental values of effective thermal coefficient $\theta_{0}=(0.01,0.03,0.05)$ is presented in Figures 5, 6, and 7. In which in Figures 5, 6, and 7 illustrates variations in transient temperature $T^{*}$ versus $y^{*}$ and $t^{*}$ for different values of $\theta_{0}$. We note that for higher values of effective thermal coefficient, the transient temperature significantly increases. Hence, effective thermal coefficient boots the transient temperature. Higher effective thermal coefficient physically implies increase in the contribution of free convection flow of air in the building envelope. The thermal comfort in the building becomes more sensitive towards higher values $\theta_{0}$, which in turn stabilizes the transient temperature in the building envelope. An increase in the height of the openings increases the transient temperature $\left(T^{*}\right)$ in the building. Therefore, it is found that the best value of $T^{*}$ for optimal natural ventilation is when $\theta_{0}=0.05$. and $t^{*}=t_{\text {max }}=1.0$. A Physical interpretation of transient temperature profiles $\left(T^{*}\right)$ for three incremental values of Prandtl number $\operatorname{Pr}=(0.650,0.710,0.770)$ is presented in Figures 8, 9, and 10. In which in Figures 8, 9, and 10 illustrates variations in transient temperature $T^{*}$ versus $y^{*}$ and $t^{*}$ for different values of $\mathrm{Pr}$. We note that for higher values of Prandtl number, the transient temperature significantly increases. Therefore, it is found that the best value of $T^{*}$ for optimal natural ventilation is when $\operatorname{Pr}=0.770$. and $t^{*}=$ $t_{\text {max }}=1.0$. A Physical interpretation of transient velocity profiles $\left(U^{*}\right)$ for three incremental values of effective thermal coefficient $\theta_{0}=(0.01,0.03,0.05)$ is presented in Figures 11, 12, and 13. In which in Figures 11, 12, and 13 illustrates variations in transient velocity profiles $\left(U^{*}\right)$ versus $y^{*}$ and $t^{*}$ for different values of $\theta_{0}$. We note that for higher values of effective thermal coefficient, the transient velocity profiles are enhanced in comparison to lower values of effective thermal coefficient. Besides, it observed that the transient velocity profiles in the building envelope increases significantly for the higher values of effective thermal coefficient. An increase in the height of the openings increases the transient velocity profiles $\left(U^{*}\right)$ in the building envelope. Therefore, it is found that the best value of $u^{*}$ for optimal natural ventilation is when $\theta_{0}=0.05$. and $t^{*}=$ $t_{\text {max }}=1.0$. A Physical interpretation of transient velocity profiles $\left(U^{*}\right)$ for three incremental values of Prandtl number $\operatorname{Pr}=(0.650,0.710,0.770)$ is presented in Figures 14, 15, and 16. In which in Figures 14, 15, and 16 illustrates variations in transient velocity profiles $\left(U^{*}\right)$ versus $y^{*}$ and $t^{*}$ for different values of $\mathrm{Pr}$. We note that for higher values of Prandtl number, the transient velocity profiles are enhanced in comparison to lower values of Prandtl number. Besides, it observed that the transient velocity profiles in the building envelope increases significantly for the higher values of Prandtl number. Therefore, it is found that the best value of $U^{*}$ for optimal natural ventilation is when $\operatorname{Pr}=0.770$. and $t^{*}=t_{\text {max }}=1.0$. A Physical interpretation of transient velocity profiles $\left(U^{*}\right)$ for three incremental values of Grashof number $G r=(10,20,30)$ is presented in Figures 17,18 , and 19. In which in Figures 17, 18, and 19 illustrates variations in transient velocity profiles $\left(U^{*}\right)$ versus $y^{*}$ and $t^{*}$ for different values of $\mathrm{Gr}$. We note that for higher values of Grashof number, the transient velocity profiles are enhanced in comparison to lower values of Grashof number. Besides, it observed that the transient velocity profiles in the building envelope increases significantly for the higher values of Grashof number. Hence, the buoyancy parameter $G r$, has the dominant effect in escalating transient velocity. Also, an increase in the height of the openings increases the transient velocity profiles $\left(U^{*}\right)$ in the building envelope. Therefore, it is found that the best value of $u^{*}$ for optimal natural ventilation is when $G r=30$. And $t^{*}=t_{\max }=1.0$. A Physical interpretation of volumetric airflow $\left(Q^{*}\right)$ for three incremental values of effective thermal coefficient $\theta_{0}=$ $(0.01,0.03,0.05)$ is presented in Figures 20,21 , and 22. In which in Figures 20, 21, and 22 illustrates variations in volumetric airflow $\left(Q^{*}\right)$ versus $y^{*}$ and $t^{*}$ for different values of $\theta_{0}$. We note that for higher values of effective thermal coefficient, the volumetric airflow is enhanced in comparison to lower values of effective thermal coefficient. Besides, it observed that the volumetric airflow in the building envelope increases significantly for the higher values of effective thermal coefficient. An increase in the height of the openings increases the volumetric airflow $\left(Q^{*}\right)$ in the building envelope. Therefore, it is found that the best value of $Q^{*}$ for optimal natural ventilation is when $\theta_{0}=0.05$. and $t^{*}=$ $t_{\text {max }}=1.0$. A Physical interpretation of volumetric airflow $\left(Q^{*}\right)$ for three incremental values of Prandtl number $\operatorname{Pr}=$ $(0.650,0.710,0.770)$ is presented in Figures 23, 24, and 25. In which in Figures 23, 24, and 25 illustrates variations in volumetric airflow $\left(Q^{*}\right)$ versus $y^{*}$ and $t^{*}$ for different values of $P r$. We note that for higher values of Prandtl number, the volumetric airflow is enhanced in comparison to lower values of Prandtl number. Besides, it observed that the volumetric airflow in the building envelope increases significantly for the higher values of Prandtl number. An increase in the height of the openings increases the volumetric airflow $\left(Q^{*}\right)$ in the building envelope. Therefore, it is found that the best value of $Q^{*}$ for optimal natural ventilation is when $\operatorname{Pr}=$ 0.770. and $t^{*}=t_{\max }=1.0$. A Physical interpretation of volumetric airflow $\left(Q^{*}\right)$ for three incremental values of 
Grashof number $G r=(10,20,30)$ is presented in Figures 26, 27, and 28. In which in Figures 26, 27, and 28 illustrates variations in Grashof number $\left(Q^{*}\right)$ versus $y^{*}$ and $t^{*}$ for different values of $G r$. We note that for higher values of Grashof number, the volumetric airflow is enhanced in comparison to lower values of Grashof number. Besides, it observed that the volumetric airflow in the building envelope increases significantly for the higher values of Grashof number. Hence, the buoyancy parameter $G r$, has the dominant effect in escalating volumetric airflow. The physics behind this phenomenon is that due to the strong effect of buoyancy forces effect an increase in volume of air in the building exerts an additional pressure on the volumetric airflow, which accelerate the airflow in the building envelope. Also, an increase in the height of the openings increases the volumetric airflow $\left(Q^{*}\right)$ in the building envelope. Therefore, it is found that the best value of $Q^{*}$ for optimal natural ventilation is when $G r=30$ and $t^{*}=t_{\max }=1.0$. A Physical interpretation of mass transfer $\left(m^{*}\right)$ for three incremental values of effective thermal coefficient $\theta_{0}=$ $(0.01,0.03,0.05)$ is presented in Figures 29,30 , and 31 . In which in Figures 29, 30, and 31 illustrates variations in mass transfer $\left(m^{*}\right)$ versus $y^{*}$ and $t^{*}$ for different values of $\theta_{0}$. We note that for higher values of effective thermal coefficient, the mass transfer is enhanced in comparison to lower values of effective thermal coefficient. Besides, it observed that the mass transfer in the building envelope increases significantly for the higher values of effective thermal coefficient. An increase in the height of the openings increases the mass transfer $\left(\mathrm{m}^{*}\right)$ in the building envelope. Therefore, it is found that the best value of $m^{*}$ for optimal natural ventilation is when $\theta_{0}=0.05$. and $t^{*}=t_{\max }=1.0$. A Physical interpretation of mass transfer $\left(m^{*}\right)$ for three incremental values of Prandtl number $\operatorname{Pr}=(0.650,0.710,0.770)$ is presented in Figures 32, 33, and 34. In which in Figures 32, 33 , and 34 illustrates variations in mass transfer $\left(m^{*}\right)$ versus $y^{*}$ and $t^{*}$ for different values of $P r$. We note that for higher values of Prandtl number, the mass transfer is enhanced in comparison to lower values of Prandtl number. Besides, it observed that the mass transfer in the building envelope increases significantly for the higher values of Prandtl number. An increase in the height of the openings increases the mass transfer $\left(\mathrm{m}^{*}\right)$ in the building envelope. Therefore, it is found that the best value of $m^{*}$ for optimal natural ventilation is when $\operatorname{Pr}=0.770$. and $t^{*}=t_{\max }=1.0$. A Physical interpretation of mass transfer $\left(m^{*}\right)$ for three incremental values of Grashof number $G r=(10,20,30)$ is presented in Figures 35, 36, and 37. In which in Figures 35, 36 , and 37 illustrates variations in Grashof number $\left(Q^{*}\right)$ versus $y^{*}$ and $t^{*}$ for different values of $G r$. We note that for higher values of Grashof number, the mass transfer is enhanced in comparison to lower values of Grashof number. Besides, it observed that the mass transfer in the building envelope increases significantly for the higher values of Grashof number. An increase in the height of the openings increases the mass transfer $\left(\mathrm{m}^{*}\right)$ in the building envelope. Therefore, it is found that the best value of $m^{*}$ for optimal natural ventilation is when $G r=30$ and $t^{*}=t_{\text {max }}=1.0$.

In order to examine the accuracy of our analytic solutions, the results are compared with most closely related results given [15]. These comparisons are shown in Figures 38, 39 and 40 respectively. It is worth mentioning that all the above comparisons of the developed model are made in terms of nondimensional variables are in in good agreement with the above stated studies given [15]. Hence, it is found that the best value for optimal natural ventilation is found to be in developed study. Therefore, expected objectives in the paper are achieved.

\section{Conclusion}

The results obtained for velocity profiles together with volumetric airflow and mass transfer of the developed study are in good agreement with the results obtained [15]. Furthermore, the findings of the study are applicable in the analysis in various branches of Architectural design, Civil and Mechanical Engineering. Main conclusions of the study are as follows:

1. An increase in $\theta_{0}, \operatorname{Pr}$ results in an increase in temperature profiles $T^{*}$ across the openings. The temperatures profiles $T^{*}$ is more sensitive at higher values of effective thermal coefficient $\theta_{0}$ and Prandtl number $P r$. An increase in the height of the openings increases the temperature profiles $T^{*}$ in the building envelope. Also, the main features to be observed is that the temperature profiles $T^{*}$ was within comfortable conditions for higher value of time intervals $t^{*}$.

2. An increase in $\theta_{0}, P r, G r$ increases the velocity profiles $U^{*}$ in the building envelope. The velocity profiles $U^{*}$ is more sensitive at higher values of flow parameters $\theta_{0}, P r, G r$. An increase in the height of the openings increases the velocity profiles $U^{*}$ in the building envelope. Also, the main features to be observed is that the velocity profiles $U^{*}$ is higher in comparison to higher value of time intervals $t^{*}$.

3. The buoyancy parameter $G r$, has the dominant effect in escalating transient velocities and volumetric airflow in the building envelope.

4. An increase in $\theta_{0}, P r, G r$ increases the volumetric airflow $Q^{*}$ in the building envelope. The volumetric airflow $Q^{*}$ is more sensitive at higher values of flow parameters $\theta_{0}, P r, G r$. An increase in the height of the openings increases the volumetric airflow $Q^{*}$ in the building envelope. Also, the main features to be observed is that the volumetric airflow $Q^{*}$ is higher in comparison to higher value of time intervals $t^{*}$.

5. An increase in $\theta_{0}, \mathrm{Pr}, \mathrm{Gr}$ increases the mass transfer $m^{*}$ in the building envelope. The mass transfer $m^{*}$ is more sensitive at higher values of flow parameters $\theta_{0}, \mathrm{Pr}, \mathrm{Gr}$. An increase in the height of the openings increases the mass transfer $m^{*}$ in the building envelope. Also, the main features to be observed is that the mass transfer $m^{*}$ is higher in comparison to higher value of time intervals $t^{*}$.

6. The greater vertical distance between the openings and the greater temperature difference between the inside and the outside, the stronger is the effect of the buoyancy. 
The model is only valid for cross- ventilated building with openings at the same height.

\section{Acknowledgements}

The authors are grateful, to authorities of Federal Government College (F. G. C), Kano and Kano University of Science \& Technology, Wudil (KUST) for granting the leave to conduct the research.

\section{References}

[1] C. Allocca, Q. Chen and L. R. Glicksman, Design analysis of single-sided natural ventilation. Building Technology, Energy and Buildings 35 (8) (2003) 785-795.

[2] H. B. Awbi and M. M. Nemri, Scale effect in room air-flow studies, Energy and Buildings, 14 (3) (1990) 207-210.

[3] H. B. Awbi, Air movement on naturally-ventilated buildings, Renewable Energy 8 (1) (1996) 241-247.

[4] C. L. Chow, Air flow rate across vertical opening induced by room heat sources, International Journal on Architectural Science 8 (1) (2010) 11-16.

[5] A. L. Muhammad and A. B. Baffa and M. Z. Ringim, Investigation of stack- driven airflow through rectangular cross- ventilated building with two openings using analytic technique, International Journal of Computer Application (IJCA) 141 (6) (2016) 5-11.

[6] A. L. Muhammad, D. A. Gano, M. Z. Ringim, S. A. Ibrahim and A. B. Baffa, Theoretical study on steady airflow through multiple upper openings inside a rectangular building in the presence of indirect flow, Communication on applied Electronics (CAE) 7 (14) (2018) 17-25.

[7] S. Duan and L. Yuguo, An example of solution multiplicity in a building with bi-directional flow openings, Indoor Built Environment 14 (5) (2005) 359-69.

[8] Y. Fan, CFD modeling of the air and contaminant distribution in rooms, Energy and Building 23 (1) (1995) 33-39.

[9] G. Gan, Evaluation of room air distribution systems using CFD, Energy and Building 23 (2) (1995) 83-93.

[10] G. Gan, Simulation of buoyancy-driven natural ventilation of buildings-impact of computational domain, Energy and building 42 (2010) 1290-1300.

[11] S. Murakami and S. Kato, Numerical and experimental study on room air flow- 3-D predictions using the K- $\varepsilon$ turbulence model, Building and Environment 24 (1) (1989) 85-97.

[12] M. W. Liddament, A review of building air flow simulation. Tech. Note AIVC 33. Air infiltration and ventilation centre, Coventry UK (1991).

[13] C. Gladstone, A. Woods, J. Philips and C. Caulfied, Experimental study of mixing in a closed room by doorway exchange flow, Proc, ROOMVENT'98. Stockholm, Sweden (1998).

[14] P. F. Linden, G. F. Lane- Serff and D. A. Smeed, Emptying filling spaces: the fluid mechanics of natural ventilation, Journal of Fluid Mechanics 212 (1990) 309-335.
[15] A. L. Muhammad, A. B. Baffa and U. M. Dauda, Transient airflow process across three vertical vents induced by Stackdriven effect inside Un- Stratified cross- ventilated rectangular building with an opposing flow in one of the upper Opening, International Journal of Computer Application (IJCA) 148 (1) (2016) 4-11.

[16] D. N. Riahi, Mathematical modeling of wind forces. Department of theoretical and applied mechanics, University of Illinois at Urbana- Champaign USA (2005) 1-14.

[17] S. C. Henry and N. K. Leslie, naturally ventilated and mixedmode buildings Part I: Thermal modeling, Building and Environment 44 (2009) 736-749.

[18] G. R. Hunt and P. F. Linden, Steady-state flows in an enclosure ventilated by buoyancy forces assisted by wind, J. Fluid Mech. 426 (2001) 355-386.

[19] Z. Luo, J. Zhao, J. Gao and L. He, Estimating natural ventilation potential considering both thermal comfort and IQA issues, Build. Environ., 42 (2007) 2289-2298.

[20] F. Roberto, Experimental and Numerical analysis of heat transfer and airflow on an interactive building façade, Energy and Buildings 42 (1) (2010) 23-28.

[21] M. Santamouris, A. Argiriou, D. Asimakopoulos, N. Klitsikas and A. Dounis, Heat and Mass- transfer through large openings by natural convection, Energy and Buildings 23 (1995) $1-8$.

[22] T. Van Hooff, and B. Blocken, CFD evaluation of natural ventilation of indoor environments by the concentration decay method: $\mathrm{CO}_{2}$ gas dispersion from a semi-enclosed stadium, Building and Environment 61 (2013) 1-17.

[23] Y. Wei, Z. Guoqiang, Y. Wei and W. Xiao, Natural ventilation potential model considering solution multiplicity, window opening percentage, air velocity and humidity in china, Building and Environment 45 (2010) 338-344.

[24] D. J. Wilson and D. E. Keil, Gravity-driven coun-terflow through an open door in a sealed room, Building and Environment 25 (1990) 379-388.

[25] W. Xin, H. Chen and C. Weiwu, Mathematical modeling and experimental study on vertical temperature distribution of hybrid ventilation in an atrium building, Energy and Buildings 41 (2009) 907-914.

[26] J. Yi and C. Qingyan, Buoyancy-driven single-sided natural ventilation in buildings with large openings, International Journal of Heat and Mass transfer 46 (2003) 973-988.

[27] A. Zollner, E. R. F. Winter and R. Viskanta, Experimental studies of combined heat transfer in turbulent mixed convection fluid flow in double- skin façades, Int. J. of Heat and mass transfer 45 (2002) 4401-4408.

[28] L. Yuguo, A. Delsante and J. Symons, Prediction of natural ventilation in buildings with large openings, Builing and Environment 35 (2000) 191-206.

[29] L. Yugou and A. Delsante, Natural ventilation induced by combined wind and thermal forces, Building and Environment 36 (1) (2001) 59-71.

[30] R. E. Britter, J. C. R. Hunt and J. C. Mumford, The distortion of turbulence by a circular cylinder, J. Fluid Mech. 92 (1979) 269-301. 
[31] L. C. James Lo, Predicting wind driven cross ventilation in buildings with small openings. Doctoral thesis. University of Texas, USA (2012).

[32] A. Acred, G. R. Hunt, A simplified mathematical approach for modelling stack ventilation in multi-compartment buildings, Builing and Environment 71 (2014) 121-130.

[33] M. Colombari and C. Balocco, Thermal behavior of interactive mechanically ventilated double glazed façade: Nondimensional analysis, Energy and Building 38 (2005) 1-7.

[34] P. Cooper and P. F. Linden, Natural ventilation of an enclosure containing two buoyancy sources, J. Fluid mechanics 311 (1996) 153-176.

[35] W. G. Brown and K. R. Solvason, Natural convection through rectangular opening in partition-I. Int. J. Heat and Mass Transfer 5 (1962a) 859-868
[36] W. G. Brown and K. R. Solvason, Natural convection heat transfer through rectangular openings in partitions-II, Int. J. Heat and Mass Transfer 5 (1962b) 869-878.

[37] P. F. Linden, The Fluid Mechanics of Natural ventilation. Annu. Rev. Fluid Mech. 31 (1) (1999) 201-238.

[38] Y. Tong, CFD and Field Testing of a naturally ventilated Fullscale Building. (Doctoral thesis) University of Nottingham, UK (2004).

[39] A. L. Muhammad, M. Z. Ringim and L. A. Isma'il, Transient investigation of stack- driven airflow process through rectangular cross- ventilated building with two vents in the absence opposing flow in the upper opening, International Journal of Engineering and Technology (IJET) 7 (3) (2018) 1249-1256. 